\title{
əEffects of Suppressed Transient Eddies by the Tibetan Plateau on the East Asian Summer Monsoon
}

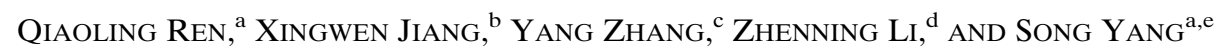 \\ ${ }^{\text {a }}$ School of Atmospheric Sciences, Sun Yat-sen University, and Southern Marine Science and Engineering Guangdong \\ Laboratory (Zhuhai), Zhuhai, China \\ ${ }^{\mathrm{b}}$ Institute of Plateau Meteorology, China Meteorological Administration, Chengdu, China \\ ${ }^{\mathrm{c}}$ School of Atmospheric Sciences, Nanjing University, Nanjing, China \\ ${ }^{\mathrm{d}}$ Division of Environment and Sustainability, Hong Kong University of Science and Technology, Hong Kong, China \\ ${ }^{\mathrm{e}}$ Guangdong Province Key Laboratory for Climate Change and Natural Disaster Studies, Sun Yat-sen University, \\ Zhuhai, China
}

(Manuscript received 15 August 2020, in final form 5 July 2021)

\begin{abstract}
It is known that the Tibetan Plateau (TP) can weaken the transient eddies (TEs) transported along the westerly jet stream. This study investigates the effects of the persistently suppressed TEs by the TP on the East Asian summer monsoon and the associated mechanisms using the NCAR Community Earth System Model. A nudging method is used to modify the suppression of the TEs without changing the steady dynamic and thermodynamic effects of the TP. The suppressed TEs by the TP weaken the East Asian westerly jet stream through the weakened poleward TE vorticity flux. On the one hand, the weakened jet stream leads to less (more) rainfall in northern (southern) East Asia by inducing anomalous moisture convergence, midtropospheric warm advection, and upper-level divergence, particularly in early summer when the eastward propagation of TE suppression by the TP is strong. On the other hand, the precipitation anomalies can shift the East Asian westerly jet stream southward and promote the moisture convergence in southern East Asia through latent heat release. Therefore, the persistent suppression of the TEs leads to a southward shift of the East Asian rain belt by a convective feedback, as it was previously found that the steady thermodynamic and dynamic forcings of the TP favored a northward shift of the rain belt. This study suggests that the anomalously weak TEs can lead to a rainfall change (more in the south, less in the north) over East Asia.
\end{abstract}

KEYWORDS: Mei-yu fronts; Monsoons; Topographic effects; Eddies; Jets

\section{Introduction}

The East Asian summer monsoon (EASM), different from the South Asian summer monsoon, is a hybrid type of tropical and subtropical monsoon (Wang and LinHo 2002; Ding and Chan 2005). It is characterized by a quasi-stationary, planetaryscale, southwest-northeast elongated rain belt, whose stepwise northward progression is synchronous with the seasonal evolutions of the upper-level East Asian westerly jet stream (EAWJS) and midtropospheric North Pacific subtropical high axis, affecting densely populated China, Japan, and South Korea (Sampe and Xie 2010; Park et al. 2015; Chiang et al. 2017; Wang et al. 2018). Its large intraseasonal and interannual variability can result in flooding, mudslides, droughts, heatwaves, and other natural disasters, influencing the socioeconomic activities in the affected regions (Ding et al. 2008; Zhang et al. 2017; Chiang et al. 2017). Thus the formation and variation of the EASM have attracted much research interest.

The Tibetan Plateau (TP) has long been shown to play a vital role in the EASM through thermal forcing, which reinforces the land-sea thermal contrast and hence favors the formation and variations of the EASM (Wu et al. 2007, 2012, 2015; Wang

¿ Denotes content that is immediately available upon publication as open access.

Corresponding author: Song Yang, yangsong3@mail.sysu.edu.cn et al. 2008; Lu et al. 2021). This is verified by the phenomenon that a realistic EASM can be simulated in a comprehensive model only when the TP is included (Liu et al. 2007; Wu et al. 2012; Park et al. 2012). More specifically, the elevated heating of the TP can drive an upper-level anticyclonic circulation (the so-called South Asian high), which exerts a significant impact on the seasonal transition of the atmospheric circulation over East Asia, and a lower-level cyclonic circulation around the $\mathrm{TP}$, which strengthens the moisture transport from tropical oceans to northern India and eastern China and favors a northward shift of the EASM rain belt.

The mechanical forcing of the TP is also important for the EASM. It deflects the airflow impinging upon the TP to produce encircling flow and a region of lower-level downstream convergence, which may be a primary driver of the EASM (Queney 1948; Wu 1984; Liu et al. 2007; Molnar et al. 2010). Chen and Bordoni (2014) further showed that the mei-yu front, the most prominent feature of the EASM, was largely maintained by the extratropical northerlies downstream of the TP, which advected dry enthalpy and strengthened the moisture convergence over central eastern China. Kong and Chiang (2020) argued that the downstream northerlies of the TP were mainly caused by the topographically forced stationary waves when the westerlies impinged on the TP. When the core of the westerlies migrates away from the TP, the mechanical forcing of the TP disappears, and so does the downstream northerly flow, leading to the demise of mei-yu rain belt. Son et al. (2019) used idealized general circulation model simulations to reveal 
(a) F2000
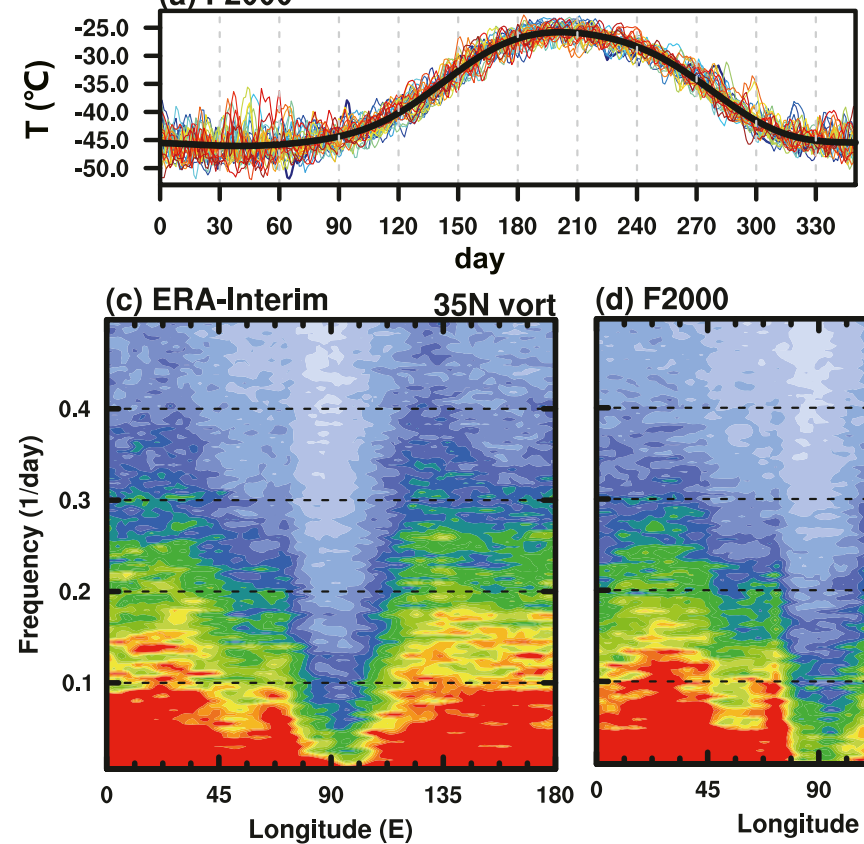

(b) NGTR

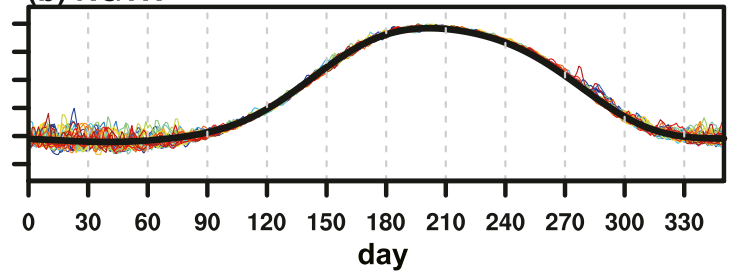

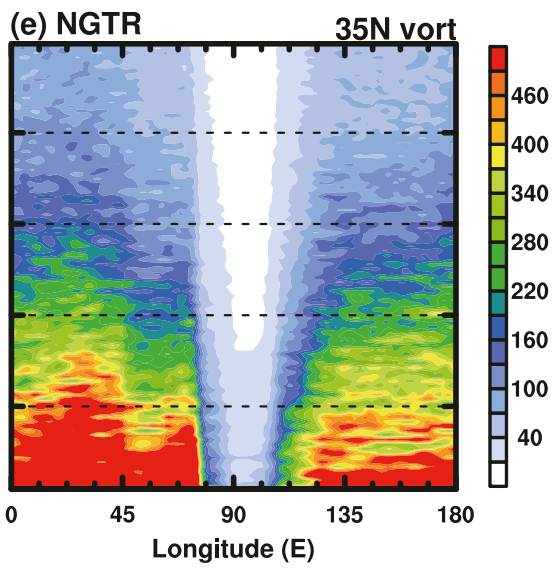
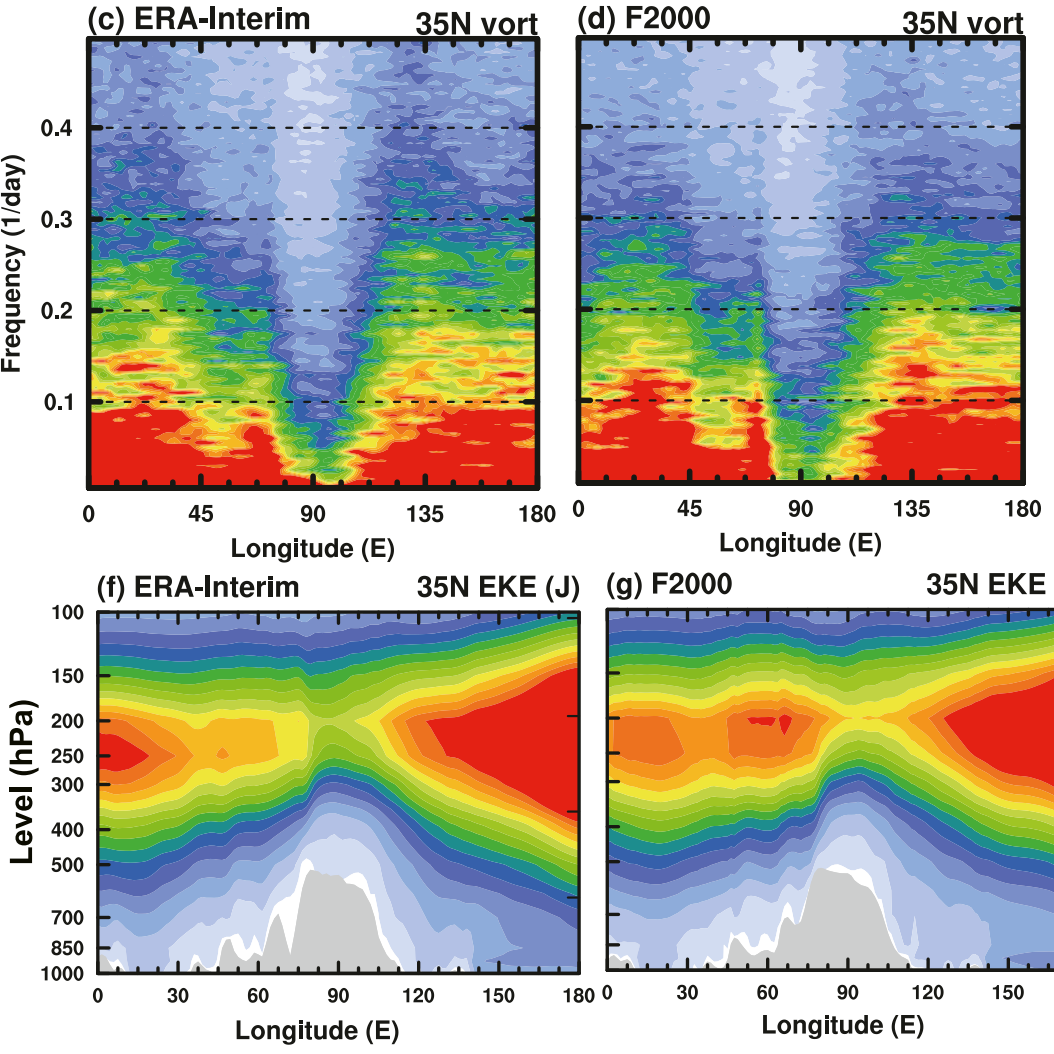

(g) F2000

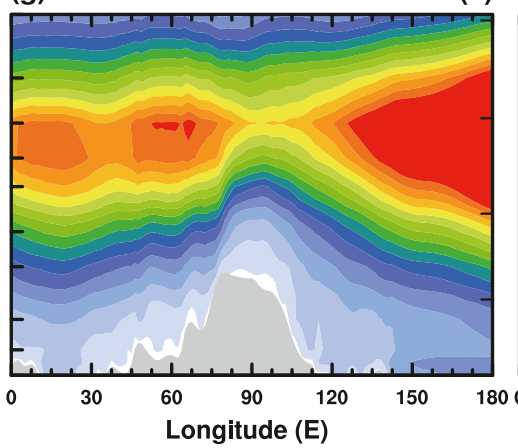

(h) NGTR

35N EKE (J)

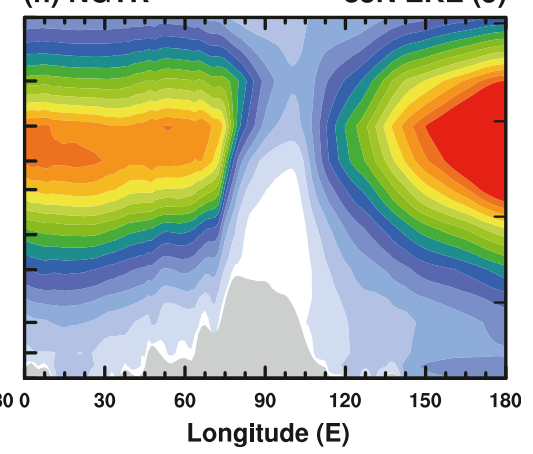

$\begin{array}{llllllllllllllll}10 & 20 & 30 & 40 & 50 & 60 & 70 & 80 & 90 & 100 & 110 & 120 & 130 & 140 & 150 & 160\end{array}$

FIG. 1. Annual cycles of area-averaged 300-hPa temperature over the TP region (where the elevation is above $3000 \mathrm{~m}$ ) in (a) F2000 and (b) NGTR, with colored lines for the daily variations in different years and the thick black line for the mean annual cycle. Power spectra of the $300-\mathrm{hPa}$ relative vorticity along $35^{\circ} \mathrm{N}$ as a function of longitude and frequency for (c) ERA-Interim reanalysis (Dee et al. 2011), (d) F2000, and (e) NGTR, following Yu and Hartmann (1995). The powers are calculated from the daily data and averaged over 50 adjacent frequency bands $\left(10^{-11} \mathrm{~s}^{-2}\right)$. Longitude-altitude sections of annual average kinetic energy of TEs $\left(\mathrm{EKE}=\int u-\bar{u}^{2}+v-\bar{v}^{2} d p ; \mathrm{J}\right.$; shading) along $35^{\circ} \mathrm{N}$ for (f) ERA-Interim, (g) F2000, and (h) NGTR, which is calculated from the daily anomalies based on the mean annual cycle of wind $(\bar{u}, \bar{v})$. The gray shading is the topography.

that the dynamical effect of TP accounted for $\sim 65 \%$ of the total EASM precipitation, demonstrating the dominant role of mechanical effects of the plateau in driving the EASM.

In addition to the thermal and mechanical forcings, many studies have found that the TP can suppress transient eddies (TEs), from high frequencies (2-10 days) to low frequencies (10-90 days), along the westerly jet stream all year round (Yu and Hartmann 1995; Chang et al. 2002; Son et al. 2009; Chang 2009; Park et al. 2010, 2013; Lee et al. 2013). As shown in Fig. 1c, the energies of both low-frequency $\left(<0.1 \mathrm{day}^{-1}\right)$ and synoptic (0.1-0.5 day $\left.{ }^{-1}\right)$ TEs rapidly decline over the TP. The responsible mechanisms that have been proposed include the orographically forced stationary waves that can change atmospheric instability and hence influence the generation and propagation of TEs (Yu and Hartmann 1995; Park et al. 2013), the mechanical obstruction that destroys the upstream eddy seeding-feeding process (Chang et al. 2002; Son et al. 2009), and the orographic drag that consumes the atmospheric momentum (Ólafsson and Bougeault 1997). Although the definitive mechanisms by which the TP suppresses the TEs remain to be determined, a number of studies have shown that this phenomenon may account for the maintenance of a stronger 
downstream meridional temperature gradient and a corresponding strong jet stream through suppressing the meridional exchange of air masses (Schiemann et al. 2009), and contribute to the midwinter suppression of the North Pacific storm track where the midlatitude cyclones often occur (Park et al. 2010; Lee et al. 2013). However, the contributions made by the suppression of TEs over the TP in shaping the EASM are not well understood.

As a crucial component of atmospheric circulation, TEs mainly develop in the midlatitudes due to enhanced baroclinicity. They not only play a key role in atmospheric transportation of mass, heat, momentum, water vapor, and other tracers (Peixoto and Oort 1992), but also influence the atmospheric circulation through wave-mean flow interactions (Cai et al. 2007; Eichelberger and Hartmann 2007; Yuan et al. 2013; Shi and Bueh 2013). For example, eddy-momentum flux convergence of TEs can lead to the midlatitude jet stream, which is also named the eddy-driven jet (Lee and Kim 2003; Li and Wettstein 2012). Different time scales of TEs play different roles in sustaining the meridional shift of the midlatitude jet stream. For low-frequency TEs, whose generation regions are away from the center of the jet, their eddy heat flux acts to enhance the lower-level baroclinicity at the center of the jet, which can strengthen the activity of high-frequency TEs since their generation regions are always located at the jet core. Following the anomalous zonal wind, eddy heat flux from the anomalous low-frequency TEs drives a latitudinal shift of the lower-level baroclinic zone, leading to a latitudinal displacement of high-frequency TEs. Then, the anomalous momentum flux from the high-frequency TEs further enhances zonal wind anomalies, establishing a positive feedback that extends the persistence of the meridional shift of the midlatitude jet stream (Zhang et al. 2012; Nie et al. 2013).

Many studies have suggested that TEs play an important role in monsoon dynamics. Using reanalysis data, Bordoni and Schneider (2008) showed that the onset of the Asian monsoon was a transition of the tropical overturning circulation in the Southern Hemisphere from an equinox regime whose strength was controlled by eddy momentum flux to a monsoon regime whose strength was more directly controlled by the thermal forcing (Schneider and Bordoni 2008). The result suggests that the feedback between TEs and tropical circulation is essential for the rapid transition of monsoon circulation. Park et al. (2015) argued that the interaction of midlatitude high-frequency TEs and the moist subtropical monsoon could enhance the circulation and precipitation of the EASM by decreasing static stability and generating quasigeostrophic ascent. Since the westerly jet stream can steer TEs, Sampe and Xie (2010) and Wang et al. (2018) regarded TEs as one of the intermediaries for the EAWJS to affect the EASM precipitation. Moreover, Chen et al. (2017) demonstrated that the midlatitude summer TEs over East Asia exhibited decadal changes due to a very strong spatial heterogeneity in the variation of surface temperature, which might contribute to the decadal variation of the EASM.

Considering the importance of the TP and TEs, it is necessary to investigate the role of the persistent suppression of TEs by the TP at all frequencies secondary to the annual cycle in the
EASM and the associated mechanisms. Since the suppression effect of the TP on TEs cannot be significantly changed in actual world, it is convenient to use model experiments for this investigation. However, two difficulties exist here, leading to little research in this area. One is in the consideration of moist processes since the EASM is characterized by rainfall, which may complicate the wave-mean flow interaction by latent heat release (Dwyer and O'Gorman 2017; Yamada and Pauluis 2017). So simplified dry models (e.g., Held and Suarez 1994), usually applied to investigate the feedback between TEs and time-mean flow, are not appropriate for this study. The other difficulty is how to distinguish the role of TE suppression by the TP from the total climatic effects of the TP including the steady dynamic and thermodynamic effects. The most commonly used method, changing the height or topography of the TP in a numerical model (Yu and Hartmann 1995; Park et al. 2010, 2013; Deng et al. 2017), not only removes the TP effects on TEs but also changes the mechanical and thermal forcings of the TP, which are essential to the EASM. Therefore, it would be unclear whether the changes in climatology are caused by the modified TEs or by the altered steady dynamic and thermodynamic forcings of the TP.

To overcome these two difficulties, a grid nudging method (also called Newton relaxation) (Kooperman et al. 2012; Tang et al. 2019) is used in a comprehensive general circulation model to modify the suppression of TEs without changing the steady dynamic and thermodynamic forcings of the TP. Thus, the differences between sensitivity experiment and control experiment are mainly driven by the suppressed TEs over the $\mathrm{TP}$, allowing us to identify how the persistent suppression of TEs by the TP influences the EASM. Here, the TEs are calculated as the departure from the mean annual cycle that is defined as the annual average plus the first four Fourier harmonics of the daily climatology (Lorenz and Hartmann 2001; Nie et al. 2013).

The details of the numerical experiments and the grid nudging method are described in section 2 . In section 3 , we portray the degree of TE suppression by the TP, its evolution from May to August, and its relationship with the westerly jet stream. The changes in atmospheric circulation and precipitation over East Asia driven by the suppression of TEs are also examined. Section 4 investigates the influence mechanisms of the suppression of TEs via the geopotential tendency equation, secondary circulation of the westerly jet stream, midtropospheric warm advection, and moisture transport. A summary and discussion are presented in section 5 .

\section{Model description}

The Community Earth System Model (CESM) version 1.2.2, a coupled climate model by the National Center for Atmospheric Research, is used in this study (Hurrell et al. 2013). It supports numerous resolutions and component configurations (combinations of different component models). Since the response of oceans to the suppressed TEs is not under consideration, for simplicity, a component set F_2000_ CAM5, in which the Community Atmosphere Model version 5 (CAM5) is coupled with the Community Land Model version 
4.0 , is employed to run for 30 years. The sea surface boundary condition is prescribed by the climatological monthly Hadley optimum interpolation (OI) sea surface temperature (SST) and sea ice concentration (SIC) datasets (HadOIB1; Hurrell et al. 2008). The settings of external forcings such as solar radiation, carbon dioxide, ozone concentration, and aerosols are all fixed at the levels of year 2000 . The atmospheric resolution is $0.9^{\circ} \times 1.25^{\circ}$ (latitude $\times$ longitude), with a hybrid vertical coordinate of 30 levels.

Two model experiments are designed to investigate the effects of suppressed TEs on the EASM. The control experiment (F2000, from the F_2000_CAM5 component set) is freely integrated according to the default settings. A grid nudging technique is employed in the sensitivity experiment (called NGTR, since it is nudged in the troposphere) to make the daily horizontal wind and air temperature over the TP region close to the mean annual cycle of F2000 (Figs. 1a,b). How this nudging method operates is shown by the following formula:

$$
\frac{\partial A}{\partial t}=F+G_{A} W_{A}\left(A_{\mathrm{clim}}-A\right)
$$

where $A$ represents the meteorological field directly calculated by the model, such as zonal wind, meridional wind, and air temperature; $A_{\text {clim }}$, the mean annual cycle of variable $A$, is the target field that needs to be approached. This formula shows that the variable tendency $\partial A / \partial t$ of the model, in which a nudging method is used, consists of two components: the model-calculated term $F$, including the physical forcing such as diabatic heating, pressure gradient force, and friction, and a nudging term $G_{A} W_{A}\left(A_{\text {clim }}-A\right) ; G_{A}$ is the relaxation factor defined by the inverse of relaxation time, which means that the model field is expected to be close to the target field within the relaxation time. The shorter the relaxation time, the stronger the relaxation intensity, which may reduce the ability of the model to deal with the mass-momentum imbalance. Considering that the goal of the nudging method is to weaken the TEs over the TP, the proper relaxation time should be less than two days, which is the minimum TE time scale. Therefore, 24-h relaxation time and 6-h relaxation time have been chosen to run the model and overall similar results are obtained. Since the TE suppression effect of the latter is better than that of the former, the relaxation time of $6 \mathrm{~h}$ is chosen to ensure both the effectiveness of the nudging method and the dynamic balance of the model. The term $W_{A}$ is the specified weighting coefficient, whose value in the $\mathrm{TP}$ region $\left(25^{\circ}-40^{\circ} \mathrm{N}, 70^{\circ}-105^{\circ} \mathrm{E}\right)$ is defined as

$$
W_{A}=\left\{\begin{array}{cl}
1 & \text { altitude } \geq 3000 \mathrm{~m} \text { (main nudging area) } \\
e^{\text {altitude }-3000} & \text { altitude }<3000 \mathrm{~m} \text { (buffer zone) }
\end{array} .\right.
$$

The original nudging code embedded in the CESM is obtained from the website https:/github.com/Novarizark/project/tree/ master/SRC_MOD_LIB-2017.

Without changing the steady dynamic and thermodynamic forcings of the TP, a straightforward way to understand the effects of TE suppression by the TP would be to fill up the TE gap over the plateau to make the distribution of TEs more uniform and then examine how the EASM responds to the condition without TE suppression by the plateau. However, it is difficult to re-establish the TEs over the TP, because the conditions of TEs such as their frequency and structure are not known when the existence of TP does not suppress the development of TEs. Therefore, a more practical experiment is to further reduce the activities of TEs over the TP using the nudging method to strengthen the TE suppression by the TP. Considering that the existence of the TP mainly suppresses the TEs below 200-hPa level as shown in Fig. 1f, the nudging method is applied in the troposphere below 200-hPa level. Because the TE suppression by the TP exists throughout the year, the activities of TEs over the TP are suppressed for the entire year in NGTR to simulate the stronger suppression effect of the TP on TEs. The experiment in which the TEs are only suppressed in summer is also analyzed and similar results are obtained (not shown), suggesting that the TE suppression by the TP in winter exerts little lag effect on summer climate.

Comparing Figs. 1c and 1f and Figs. 1d and 1g, F2000 can generally simulate the distribution of TEs, especially the rapid decrease over the TP. Figures $1 \mathrm{e}$ and $1 \mathrm{~h}$ exhibit that both the high-frequency and low-frequency TEs over the TP are further reduced in NGTR as expected, which means that the grid nudging has successfully modified the suppression of TEs over the TP. Examination of the relative relationship between topography and circulation and the thermal contrast between the TP and its surrounding air suggests that the steady dynamic and thermodynamic effects of the TP on the EASM remain effectively unchanged in NGTR (see the appendix). Thus, the differences between NGTR and F2000 are mainly caused by the suppression of TEs over the TP.

A model experiment in which the TP is removed (noTP) through changing the height of the TP to $1 \mathrm{~km}$ is also analyzed, which will be discussed in section 5. Although the general atmospheric circulation is completely changed in noTP, comparing the distribution of EKE between F2000 and noTP can help us to understand the suppression effect of the TP on TEs. However, noTP cannot be used to investigate how the suppression of TEs by the TP influences the EASM since the steady dynamic and thermodynamic forcings of the TP have been substantially changed.

\section{Characteristics of suppressed TEs and related climate variation in summer}

Considering the relatively high altitude of the TP, the uppertropospheric kinetic energy of TEs [eddy kinetic energy (EKE)] vertically integrated from 500 to $200 \mathrm{hPa}$ is used to characterize the horizontal distribution of TEs and propagation of the suppression effect of the TP on TEs. Since the upper-level westerly jet stream is a waveguide for TEs, it has also been drawn as the violet contours in Fig. 2. The left column of Fig. 2 shows that the EKE is largely concentrated in the midto-higher latitudes and develops downstream along the westerly jet stream. However, the TEs over the TP are weaker than those over the same latitudes, confirming that the TP can suppress the TEs transported from the upstream regions in summer. There are also some locally generated TEs over the eastern TP and downstream regions due to the rapid change 
(a) F2000 May
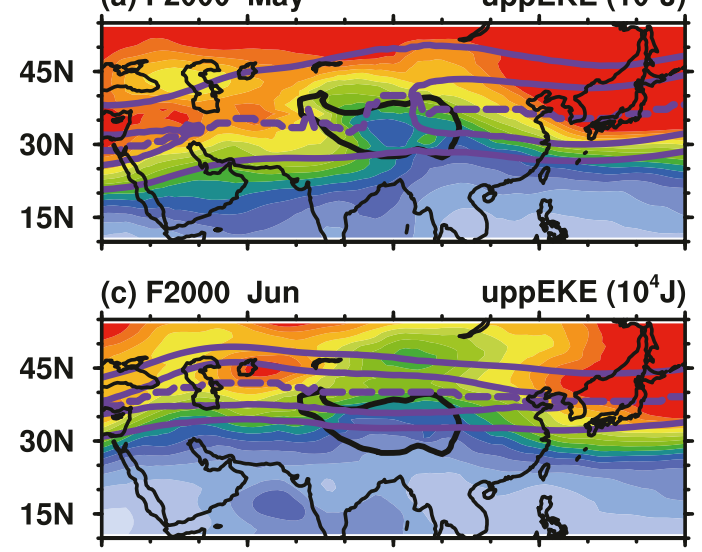

(e) F2000 Jul

UPPEKE $\left(10^{4} \mathrm{~J}\right)$

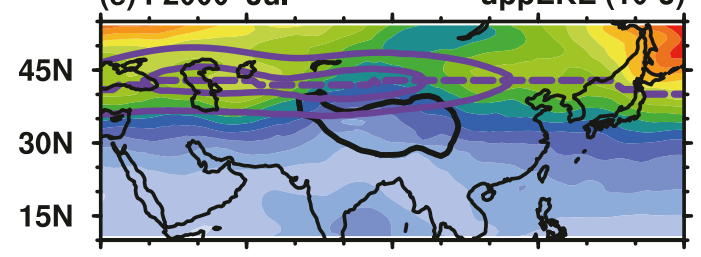

(g) F2000 Aug

UPpEKE $\left(10^{4} \mathrm{~J}\right)$

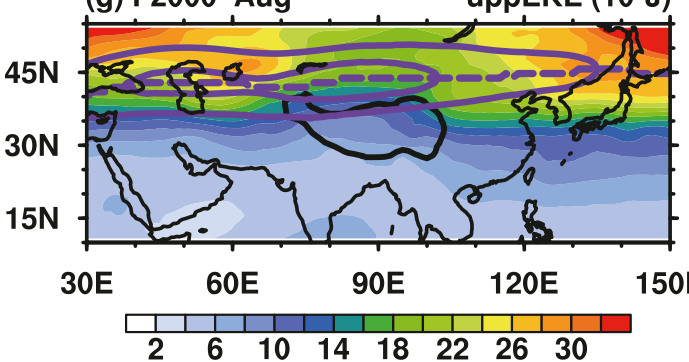

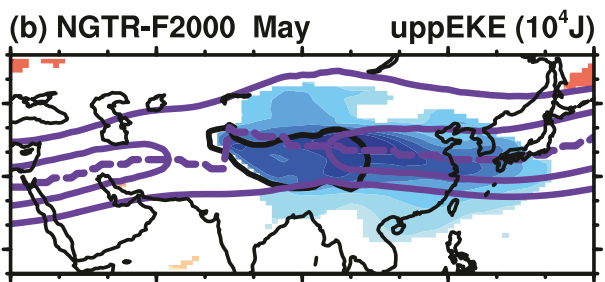
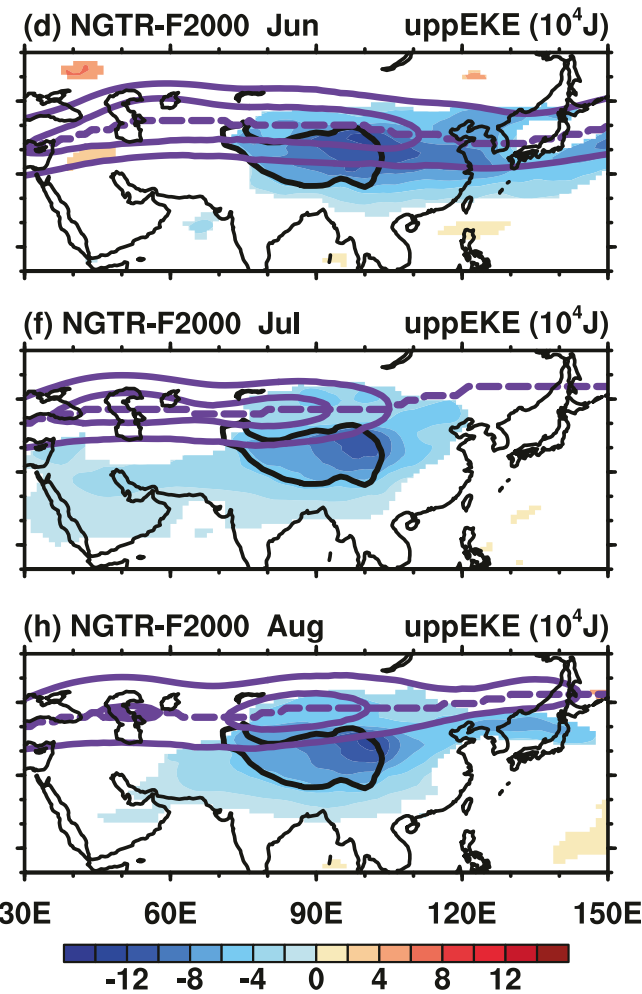

FIG. 2. (left) Vertically integrated climatic EKE from 500 to $200 \mathrm{hPa}$ in F2000 ( $10^{4} \mathrm{~J}$; shading) and (right) as in the left panels, but for the difference between F2000 and NGTR (in which the values significantly exceeding the $95 \%$ confidence level of Student's two-sided $t$ test are shaded), for (a),(b) May, (c),(d) June, (e),(f) July, and (g),(h) August. Violet contours represent the climatological 200-hPa westerly wind (contour values: 20 and $30 \mathrm{~m} \mathrm{~s}^{-1}$ ) in F2000 and NGTR, and the dashed ones mark the axis of the 200-hPa westerly jet stream. Thick black curves indicate the elevation above $3000 \mathrm{~m}$.

from high topography to relatively flat terrain, the strong downstream meridional temperature gradient, and the effect of the EASM intraseasonal variations. The areas of high EKE experience poleward contraction, with the northward jump of the westerly jet stream.

Since TEs mainly propagate and develop along the jet stream, the existence of the TP suppresses not only the TEs over the TP, but also the TEs over downstream regions due to fewer TEs being transported along the jet stream from the upstream to downstream regions (Chang et al. 2002; Son et al. 2009; Park et al. 2010). The right column of Fig. 2 describes the weakened TEs over the downstream regions that mainly depend on the meridional position of the westerly jet stream. When the jet stream is mainly located over the central TP in May, the effects of the suppressed TEs extending from the North China Plain to Japan are the strongest (Fig. 2b). The situation in June is similar to that in May, except that the scope and intensity of the effects are slightly reduced (Fig. 2d). In July, as the westerly jet stream moves to the north of the TP and becomes the weakest, the affected regions move northward to the Northeast China Plain and the strength of the effects is further weakened (Fig. 2f). The condition in August is similar to that in July, except for the faintly stronger intensity of the effects (Fig. 2h), given that the westerly jet stream begins to strengthen at the end of summer (Fig. $2 \mathrm{~g}$ ), allowing the affected areas to extend to Japan. Due to similar effects of the weakened TEs by the TP in May and June, also in July and August, summer is divided into early and late summers in the rest of the analysis.

Figures 3 and 4 show the climatological precipitation, apparent heat source vertically integrated from the surface to $200 \mathrm{hPa}$ (Yanai and Tomita 1998), and horizontal winds at 
(a) F2000 MJ

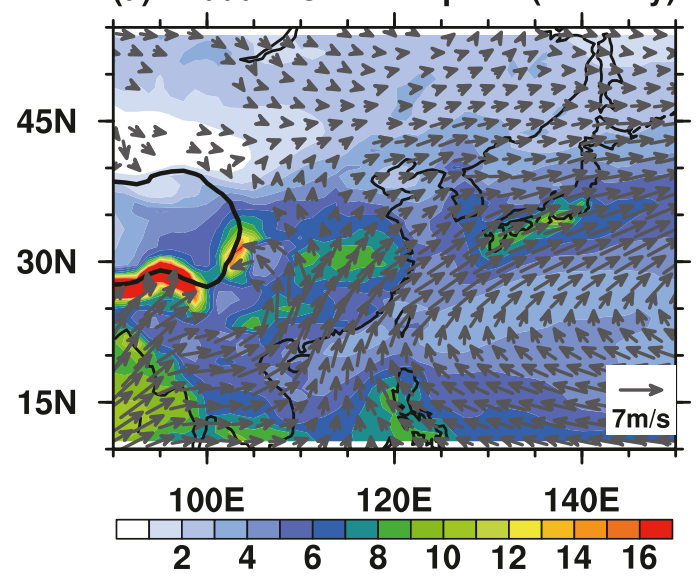

(c) NGTR-F2000 MJ preci (mm/day)

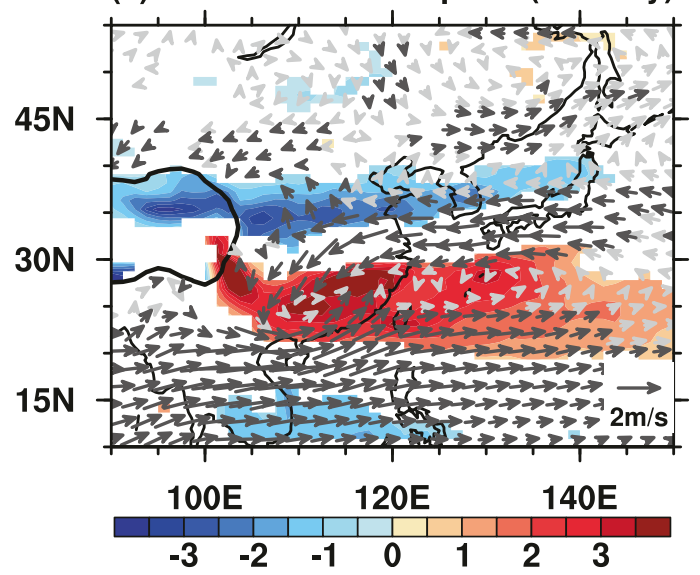

(b) F2000 MJ

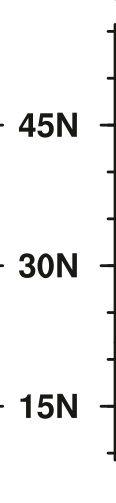

Q1 $(\mathrm{W} / \mathrm{kg})$
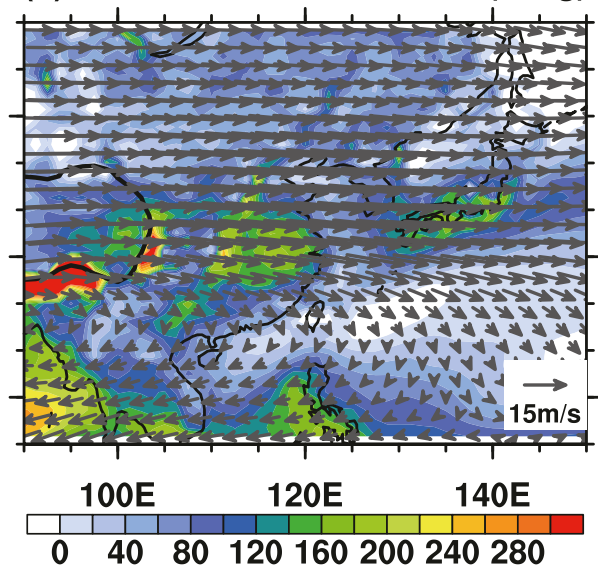

(d) NGTR-F2000 MJ Q1 (W/kg)
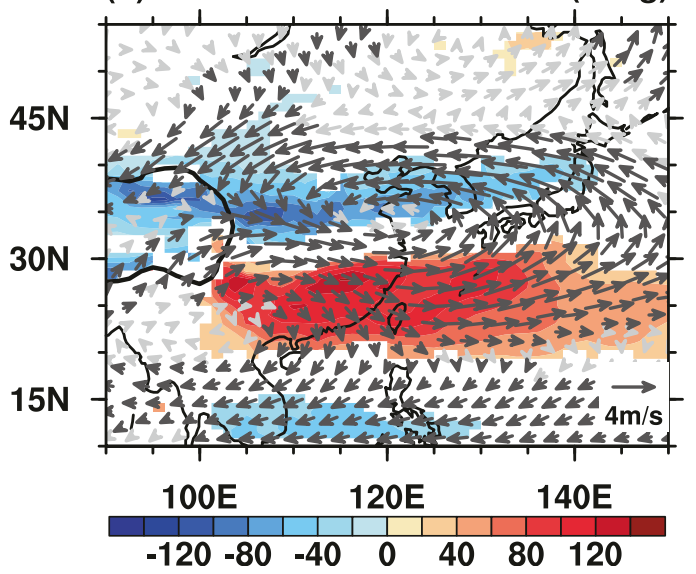

FIG. 3. Climatology of (a) precipitation ( $\mathrm{mm} \mathrm{day}^{-1}$; shading) and $850-\mathrm{hPa}$ horizontal wind ( $\mathrm{m} \mathrm{s}^{-1}$; vector), and (b) vertically integrated apparent heat source $\left(\mathrm{W} \mathrm{kg}^{-1}\right.$; shading) and 200-hPa horizontal wind ( $\mathrm{m} \mathrm{s}^{-1}$; vector) in F2000 for early summer (May and June). Thick black curves indicate the elevation above $3000 \mathrm{~m}$. (c),(d) As in (a) and (b), respectively, except for the differences between NGTR and F2000, with color shading and black arrows denoting the areas where the differences significantly exceed the $95 \%$ confidence level of Student's two-sided $t$ test.

850 and $200 \mathrm{hPa}$ in early and late summers. The apparent heat source represents the total diabatic heating, which can be calculated as the residual of the thermodynamic equation:

$$
Q_{1}=c_{p}\left[\frac{\partial T}{\partial t}+\mathbf{V}_{h} \cdot \nabla T-\omega\left(\frac{R T}{c_{p} p}-\frac{\partial T}{\partial p}\right)\right],
$$

where $\mathbf{V}_{h}$ and $\omega$ mean the horizontal wind and vertical $p$ velocity, respectively; $R$ is the gas constant, set to $287 \mathrm{~J} \mathrm{~kg}^{-1} \mathrm{~K}^{-1}$, and $c_{p}$ is the specific heat capacity at the constant pressure for air, set to $1004 \mathrm{~J} \mathrm{~kg}^{-1} \mathrm{~K}^{-1}$. The rainband is primarily located in southern China and southern Japan in early summer when northern East Asia (north of $30^{\circ} \mathrm{N}$ ) is controlled by strong westerly wind at $200 \mathrm{hPa}$ and the moist low-level southerlies can only reach $35^{\circ} \mathrm{N}$ (Figs. 3a,b). In late summer, the upperlevel westerly jet stream moves northward to $38^{\circ} \mathrm{N}$, the lowerlevel monsoonal southerlies advance to the Northeast China Plain, and the rain belt also shifts to northern East Asia (Figs. 4a,b). The distribution of apparent heat source is similar to that of rainfall, implying that the apparent heat source is essentially driven by the latent heat of condensation (Figs. 3 and 4).

When the suppression of TEs by the TP is reinforced, more (less) precipitation appears in southern (northern) East Asia in early summer, accompanied by an anomalous north anticyclonesouth cyclone circulation pattern at the lower level (Fig. 3c) and north cyclone-south anticyclone anomalies at the upper level (Fig. 3d). These anomalous circulations exhibit a baroclinic structure that may be driven by the anomalous north coolingsouth heating apparent heat source, a result of the anomalous latent heat release (Figs. 3c,d). Considering that we only change the intensity of TEs over the TP in NGTR, the anomalous circulations may also be caused by the TEs via wave-mean flow interaction, which will be discussed in the next section. In late summer, in spite of the northward shift of the climatic background (the mean state), the dipole-like rainfall anomalies still exist with a smaller amplitude and a northward movement, as does the anomalous circulation pattern at the lower level (Fig. 4c). But there exists only an anomalous cyclone at the 
(a) F2000 JA

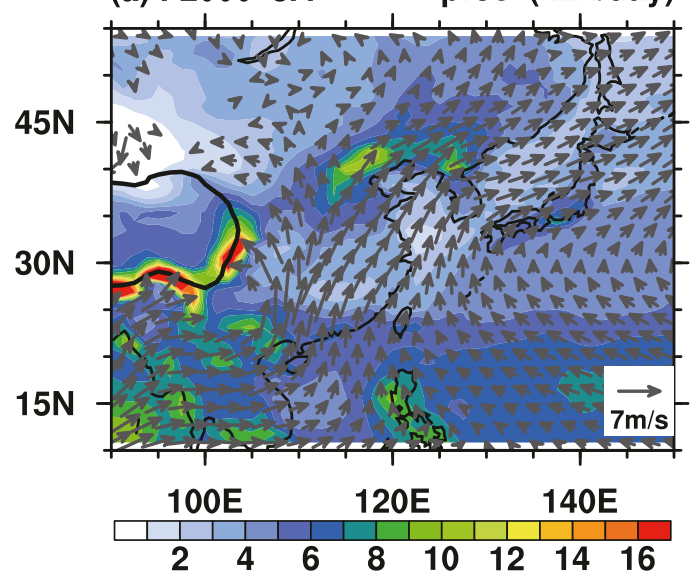

(c) NGTR-F2000 JA preci (mm/day)

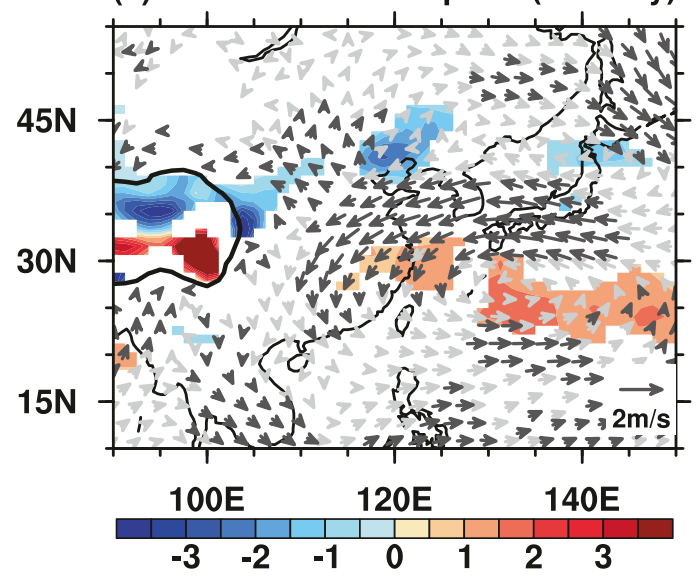

(b) F2000 JA

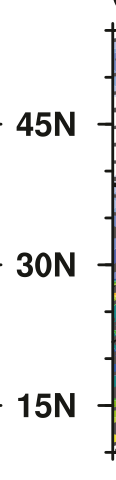

Q1 $(\mathrm{W} / \mathrm{kg})$

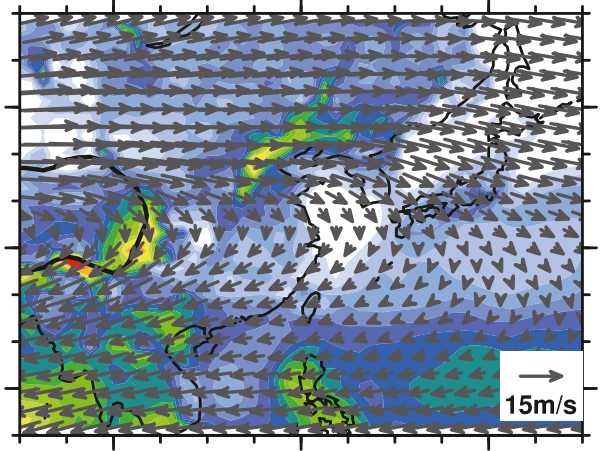

100E

$120 \mathrm{E}$

$140 \mathrm{E}$

$0 \quad 40 \quad 80120160200240280$
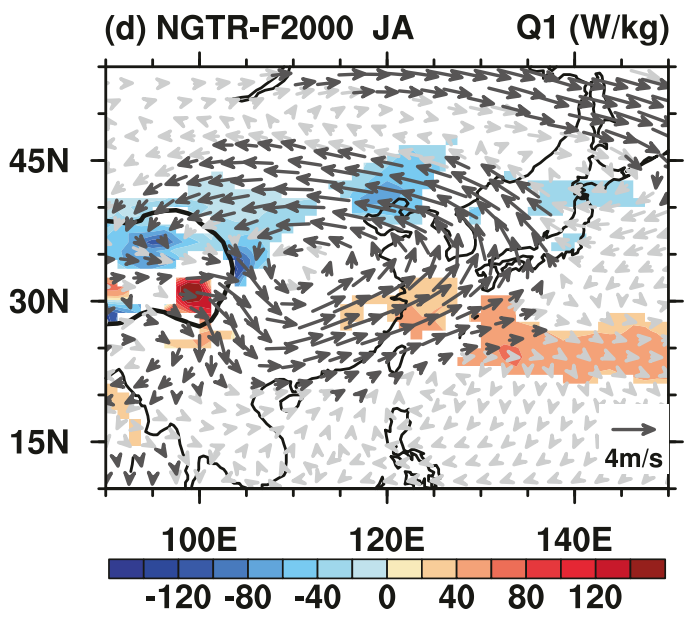

FIG. 4. As in Fig. 3, but for late summer (July and August).

upper level over East Asia accompanied by the dipole of weak anomalous apparent heat source (Fig. 4d). These weak anomalies may result from the weak eastward propagation of TE suppression by the TP in late summer (right column of Fig. 2).

The vertical structures of the EAWJS averaged between $110^{\circ}$ and $130^{\circ} \mathrm{E}$ in F2000 and NGTR (denoted by black contours in Fig. 5) are also analyzed due to its close relevance to both the EASM and TEs. It can be seen that the EAWJS in NGTR lies more southward than that in F2000 in early summer (Fig. 5c), similar to the pattern shown in Fig. 3d wherein the upper-level westerly wind intensifies (weakens) in the south (north). In late summer, the EAWJS in NGTR shifts northward and weakens (Fig. 5d). The structure of anomalous zonal wind is baroclinic in early summer (Fig. 5e) and barotropic in late summer (Fig. 5f), suggesting that there may be different mechanisms for these anomalous circulations. Given that the meridional position of EAWJS plays a crucial role in the stepwise transition of East Asian summer rainfall (Chiang et al. 2015, 2017; Wang et al. 2018; Kong and Chiang 2020), it is essential to explore what leads to such changes in the EAWJS, which may lead to the south more-north less rainfall anomalies.

\section{Mechanisms for changes in atmospheric circulation and precipitation}

\section{a. Circulation diagnosis via geopotential tendency equation}

In light of the above analysis, the latent heating and TEs, both of which can drive the anomalous circulation, have been changed in NGTR. To better understand their individual contributions to anomalous circulation, the geopotential tendency equation (Lau and Holopainen 1984) derived from the quasigeostrophic potential vorticity equation under hydrostatic approximation is used, which can be written as follows:

$$
\begin{aligned}
{\left[\frac{1}{f} \nabla^{2}+f \frac{\partial}{\partial p}\left(\frac{1}{\widetilde{\sigma}} \frac{\partial}{\partial p}\right)\right] \frac{\partial \bar{\Phi}}{\partial t}=} & -f \frac{\partial}{\partial p}\left(\frac{\alpha}{\widetilde{\widetilde{\sigma}}} \frac{\overline{Q_{d}}}{\bar{T}}\right)-f \frac{\partial}{\partial p}\left(\frac{\alpha}{\widetilde{\bar{\sigma}}} \frac{\overline{Q_{\mathrm{te}}}}{\bar{T}}\right) \\
& +\overline{F_{\mathrm{te}}}+R_{v}
\end{aligned}
$$

where the overbar denotes the daily climatology, and $\partial \Phi / \partial t$ is geopotential tendency; $\widetilde{\widetilde{\sigma}}$ is the hemispheric mean of the climatic static stability parameter $\bar{\sigma}=-(\alpha / \bar{\theta})(\partial \bar{\theta} / \partial p)$, which is only a function of pressure $p$. The terms $\theta$ and $\alpha$ are, respectively, the potential temperature and the specific volume; $\overline{Q_{d}}$ is 
(a) F2000 MJ

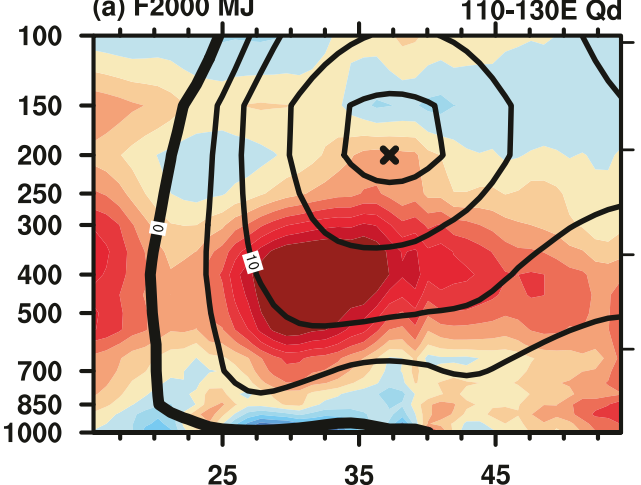

(c) NGTR-F2000 MJ

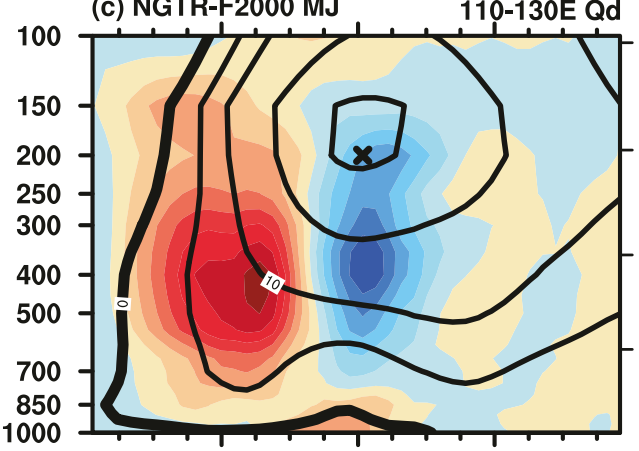

25

35

(e) NGTR-F2000 MJ
110-130E Qd

45 110-130E Qd

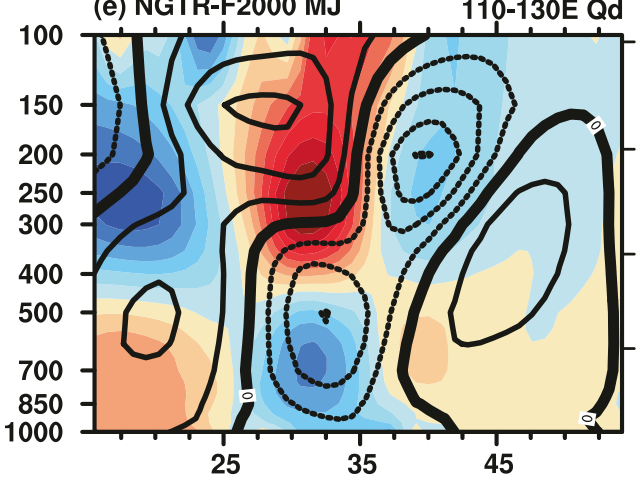

(b) F2000 JA

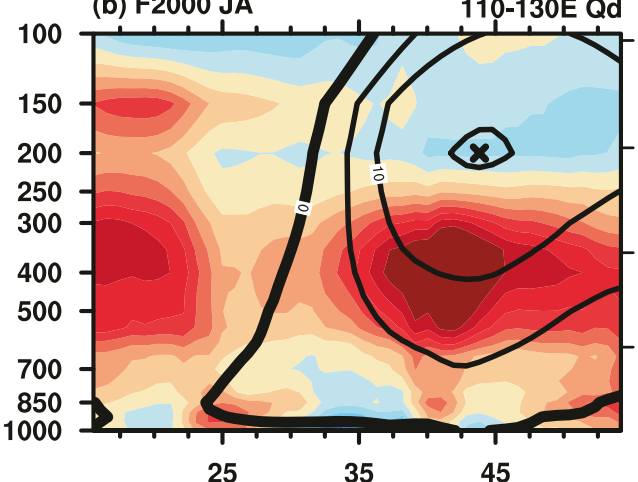

(d) NGTR-F2000 JA

110-130E Qd
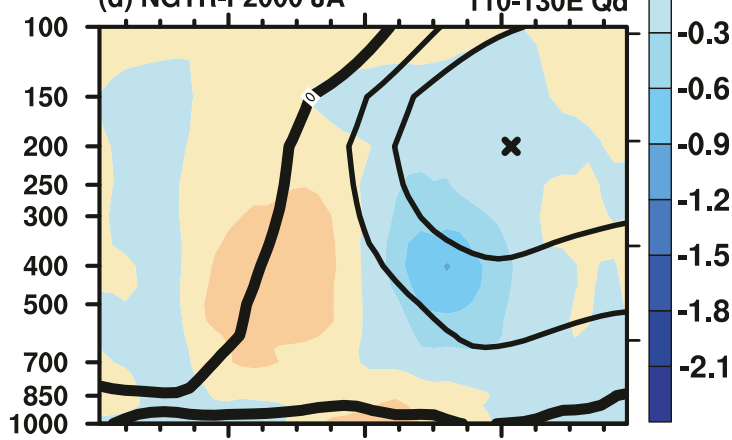

25

35

45

(f) NGTR-F2000 JA 110-130E Qd

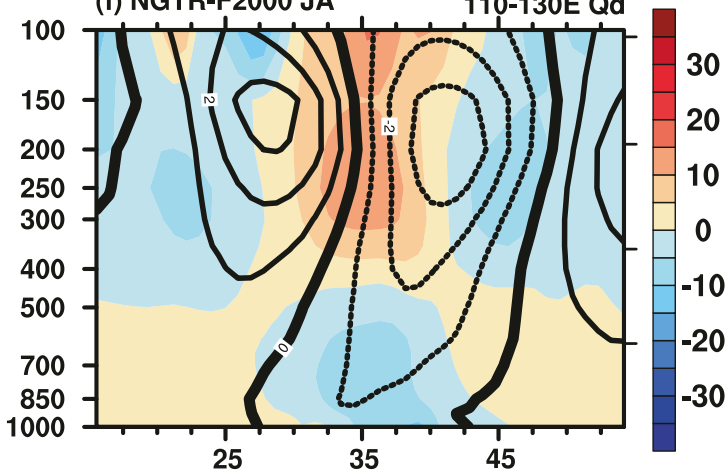

FIG. 5. Latitude-altitude sections of climatological (a),(b) diabatic heating in F2000, (c),(d) its difference between NGTR and F2000 (K day ${ }^{-1}$; shading), and (e),(f) the geostrophic zonal wind tendencies $\left(10^{-6} \mathrm{~s}^{-2}\right.$; shading) driven by the anomalous diabatic heating shown in (c) and (d) averaged between $110^{\circ}$ and $130^{\circ} \mathrm{E}$ for (left) early summer and (right) late summer. The black contours represent the climatological westerly wind in F2000 in (a) and (b) and NGTR in (c) and (d), and its difference between NGTR and F2000 in (e) and (f). Contour values are 0 (bold), 5, 10, 20, and $30 \mathrm{~m} \mathrm{~s}^{-1}$ in (a)-(d) and the contour interval in (e) and (f) is $1 \mathrm{~m} \mathrm{~s}^{-1}$. The black cross in (a)-(d) denotes the jet core.

the daily climatology of diabatic heating, which can be written as

$$
\begin{aligned}
\overline{Q_{d}} & =\overline{\mathbf{V}_{h} \cdot \nabla T}-\overline{\left(\frac{R T}{c_{p} p}-\frac{\partial T}{\partial p}\right) \omega} \\
& =\bar{V}_{h} \cdot \nabla \bar{T}-\left(\frac{R \bar{T}}{c_{p} p}-\frac{\partial \bar{T}}{\partial p}\right) \bar{\omega}-\overline{Q_{\mathrm{te}}} .
\end{aligned}
$$

It is the time mean form of $Q_{1} / c_{p}$, since the small time-averaged temperature tendency can be ignored. Transient eddy heating
$\overline{Q_{\text {te }}}$ is caused by the heat flux transported by TEs, calculated according to the following formula:

$$
\overline{Q_{\mathrm{te}}}=-\nabla \cdot \overline{\mathbf{V}_{h}^{\prime} T^{\prime}}-\frac{\partial \overline{\omega^{\prime} T^{\prime}}}{\partial p}+\frac{R}{c_{p} p} \overline{\omega^{\prime} T^{\prime}}
$$

where the prime denotes the daily anomaly departed from the mean annual cycle. Transient eddy vorticity forcing $\overline{F_{\text {te }}}$ is determined by the convergence of TE vorticity flux: 


$$
\overline{F_{\mathrm{te}}}=-\nabla \cdot \overline{\mathbf{V}_{h}^{\prime} \zeta^{\prime}}
$$

The term $R_{v}$ is a residual term including the horizontal advection of quasigeostrophic potential vorticity and friction. Since the climate states are generally in equilibrium, the total geopotential tendency driven by the four terms on the righthand side of Eq. (4) is close to zero, suggesting that the effect of the residual term is reverse to the total effects of the other three terms. Considering that the residual term is caused by the atmospheric circulation driven by above three forcings, it can modulate the effects of above three forcings but cannot completely change them. Hence, Eq. (4), computed using the daily wind and temperature from F2000 and NGTR that have been adjusted by advection processes, can be used to qualitatively diagnose the climatological structures of the above three forcings and their respective effects on the atmosphere, as has been done in many other studies (e.g., Xiang and Yang 2012; Fang and Yang 2016).

Because of the complex terrain that leads to missing values at the lower level, the horizontal winds at the 1000- and 925-hPa levels are derived from geopotential height using the geostrophic relationship. Then, Eq. (4) is solved for the Northern Hemispheric domain extending vertically from 1000 to $100 \mathrm{hPa}$ with a 50 -hPa vertical resolution and meridionally from $10^{\circ}$ to $90^{\circ} \mathrm{N}$ using the successive overrelaxation (SOR) method (Mayooran and Light 2016) to obtain geopotential tendencies driven by different forcings. As in Lau and Holopainen (1984), the boundary conditions are taken to be $(\partial / \partial y)(\partial \Phi / \partial t)=0$ at the north pole, $\partial \Phi / \partial t=0$ at $10^{\circ} \mathrm{N},[(\partial / \partial p)(\partial \Phi / \partial t)]_{1000 \mathrm{hPa} / 100 \mathrm{hPa}}=-(R / p) Q_{1000 \mathrm{hPa} / 100 \mathrm{hPa}}$ at the vertical boundaries for diabatic heating and TE heating, and $[(\partial / \partial p)(\partial \Phi / \partial t)]_{1000 \mathrm{hPa} / 100 \mathrm{hPa}}=0$ for TE vorticity forcing. The geostrophic zonal wind tendencies are calculated by $\partial u / \partial t=-(1 / f)(\partial / \partial y)(\partial \Phi / \partial t)$. Only the data zonally averaged between $110^{\circ}$ and $130^{\circ} \mathrm{E}$ are examined.

A striking feature of the EASM is the rain belt that jumps meridionally with the EAWJS, generating diabatic heating in the midtroposphere to the south of the jet axis via latent heat release (Figs. 5a,b). Because this rain belt primarily results from the interaction between the warm humid air from the south and the cold air from the north ( $\mathrm{Li}$ et al. 2019), its diabatic heating profile is shallower than that of the deep convection in the tropics. The differences in diabatic heating between NGTR and F2000 exhibit a dipole pattern (Figs. 5c,d) in both early and late summer, consistent with the rainfall changes shown in Figs. $3 \mathrm{c}$ and $4 \mathrm{c}$. This anomalous diabatic heating creates a baroclinic atmospheric response, inducing the westerly-easterly-westerly wind tendencies at the lower level and easterly-westerly-easterly wind tendencies in the upper troposphere according to Eq. (4), which shift northward and weaken in late summer (Figs. 5e,f).

As is well known, the thermal transport by TEs is always down the heating gradient and tends to heat the areas where diabatic heating is weak (Peixoto and Oort 1992). From the global zonal mean, the solar radiation heating in low latitudes is greater than that in high latitudes, thus favoring poleward TE heat flux; this acts to cool the low latitudes and to heat up the higher latitudes. Over East Asia, with the strong latent heat release in the midtroposphere in summer, the vertical TE heat flux becomes greater. This heats the upper levels and cools the lower levels, dominating the total TE heating in F2000 (Fig. 6a). According to the diagnostic analysis of Eq. (6) (figure not shown), the convergence of the horizontal TE heat flux also contributes to the cooling in the middle and lower troposphere shown in Fig. 6a. When the TEs transported to East Asia are suppressed by the TP, the TE heat fluxes in all three directions listed in Eq. (6) weaken, producing an anomalous cooling on the north side of the jet core and anomalous heating on the south side of the jet core and the lower troposphere (Fig. 6c). The distribution of this anomalous TE heating tends to accelerate the westerly winds over the jet core (Fig. 6e). Both the climatology in F2000 and differences between F2000 and NGTR of TE heating become weaker and migrate northward in late summer (Figs. 6b,d,f), consistent with the movement of the westerly jet stream and the weakening TEs.

The analytic solutions of Eq. (4) based on a simplified system (Lau and Holopainen 1984) show that the convergence of TE vorticity flux (positive TE vorticity forcing) can induce negative geopotential tendency that tends to generate a cyclone and hence accelerates the westerly wind on its equatorward side. Figure 7a shows that there is a major upper-level convergent center of TE vorticity flux at the poleward side of the EAWJS. This TE vorticity forcing does not exhibit an equivalent barotropic structure as shown in Fig. 5d from Fang and Yang (2016), because the summer TEs over East Asia are not as strong as the winter TEs over the North Pacific; however, it can still generate eastward acceleration throughout the entire troposphere north of $42^{\circ} \mathrm{N}$, with the strongest magnitude at $250 \mathrm{hPa}$ (figure not shown). Due to the reinforced TE suppression by the TP, the northward TE vorticity flux weakens so much in early summer that the convergence of TE vorticity flux at the axis of the westerly jet stream almost becomes a divergence center and a convergence center appears on the equatorward side of the westerly jet stream (Fig. 7c), which causes reduced westerly wind at the EAWJS core and accelerations on both sides of the jet stream (Fig. 7e). With the poleward shift of the EAWJS, this anomalous barotropic pattern becomes weaker and shifts northward in late summer (Figs. 7d,f). The chaotic TE vorticity forcing below the 900-hPa level, shown in Figs. 7a and 7b, caused by the complex terrain can be disregarded because different values of this chaotic forcing can yield similar results.

The above results in Figs. 5-7 show directly how the different forcings have changed in the new quasi-balanced state. Although the change in different forcing terms may not tell us exactly how the circulation reaches the new equilibrium, it is reasonable to expect that the terms that most resemble the zonal wind anomalies are most likely the driver and that the other terms have responded to balance this in the new equilibrium. By comparing the structures of above zonal wind tendencies with that of the zonal wind anomaly (bottom rows in Figs. 5-7), it can be found that the baroclinic anomalous zonal wind in early summer is most similar to the zonal wind tendency driven by the anomalous diabatic heating (Fig. 5e) while the barotropic anomaly in late summer is most similar to the zonal wind tendency driven by the anomalous TE vorticity forcing (Fig. 7f). This phenomenon suggests that the anomalous 
(a) F2000 MJ

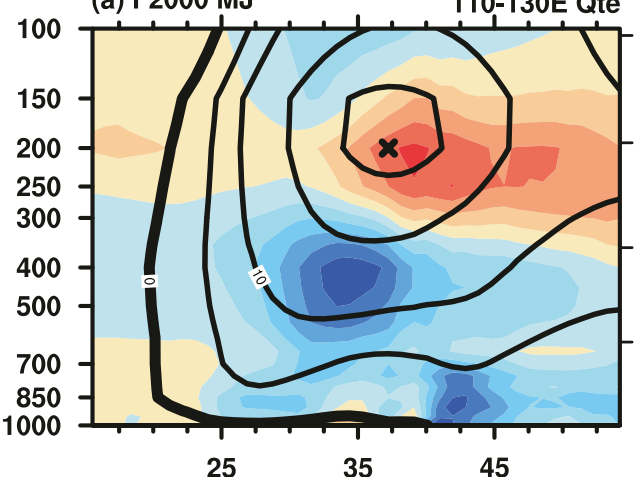

(c) NGTR-F2000 MJ

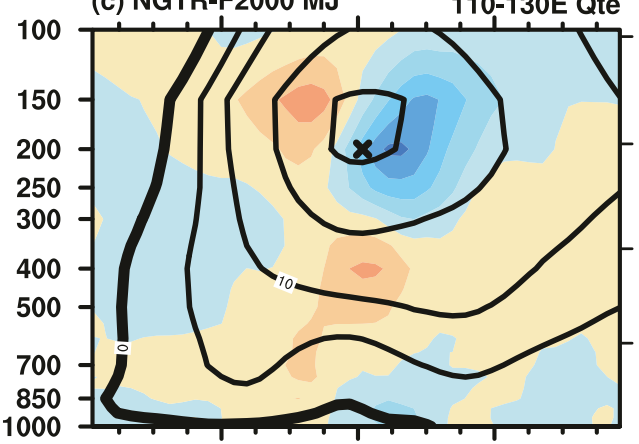

25

35

(e) NGTR-F2000 MJ

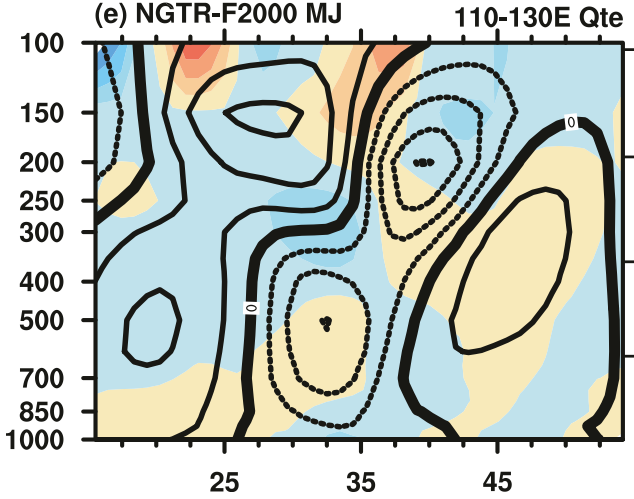

(b) F2000 JA

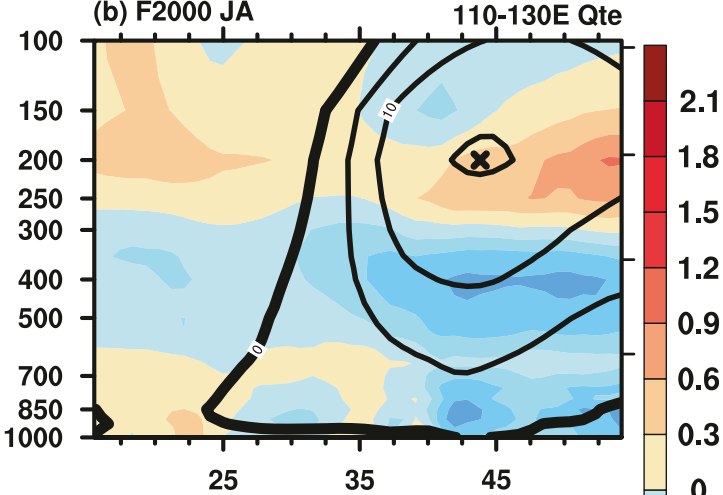

(d) NGTR-F2000 JA

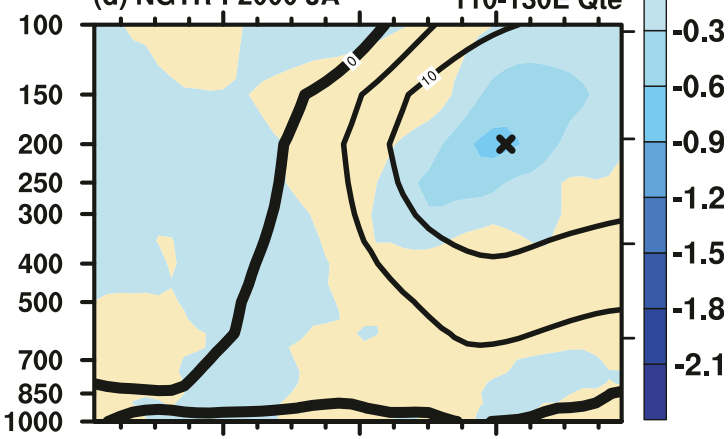

45

$25 \quad 35$

35 110-130E Qte

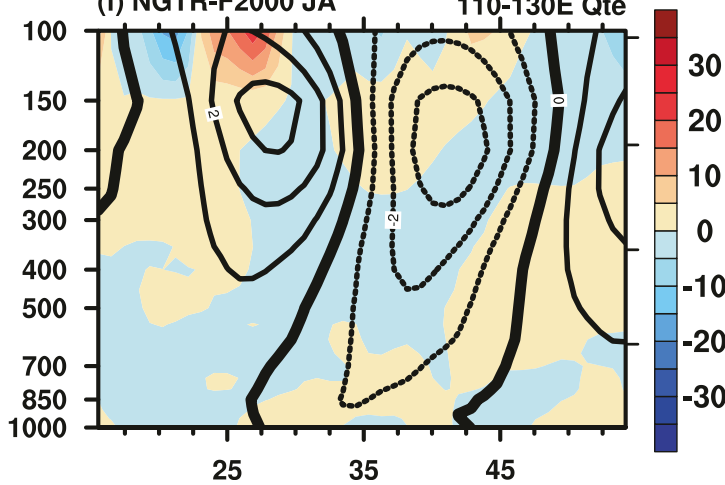

FIG. 6. As in Fig. 5, but for climatological transient eddy heating $\left(\mathrm{K} \mathrm{day}^{-1}\right)$.

diabatic heating contributes most to the anomalous circulation in early summer, favoring a southward displacement of the EAWJS, while the anomalous TE vorticity forcing is mainly responsible for the weak EAWJS in late summer.

Given that the only difference of model setup between F2000 and NGTR is the intensity of TEs over the TP, which leads to the always existing anomalous TE vorticity forcing, the deceleration of the EAWJS caused by anomalous TE vorticity forcing also exists all year around (Fig. 7f). However, due to the strong diabatic heating anomalies caused by the anomalous rainfall in early summer, there exists an anomalous baroclinic circulation, concealing the effect of TE vorticity forcing (Fig. 5e). Then, the questions that arise are how the deceleration of the EAWJS leads to the anomalous rainfall and why this anomalous rainfall is stronger in early summer than in late summer (Figs. 3c and 4c). Since the effect of TE vorticity forcing in late summer is not severely contaminated by the diabatic heating, the anomalous conditions in late summer are primarily examined next to solve the above two questions.

\section{b. Physical processes behind precipitation change}

According to the zonal momentum equation (Holton 2004),

$$
\frac{d u}{d t}=f\left(v-v_{g}\right)+F
$$

where $v_{g}=(1 / f)(\partial \Phi / \partial x)$ is the meridional component of the geostrophic wind that is nondivergent, $f v_{g}$ represents the pressure gradient force, and $F$ is the surface friction that can be neglected at the upper level, there is a poleward ageostrophic 
(a) F2000 MJ

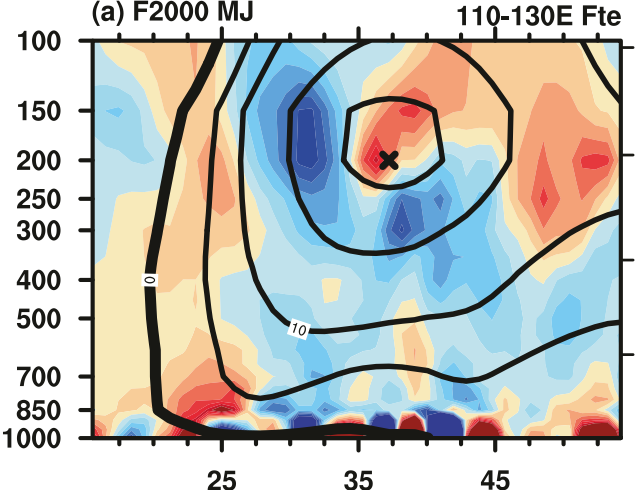

(c) NGTR-F2000 MJ

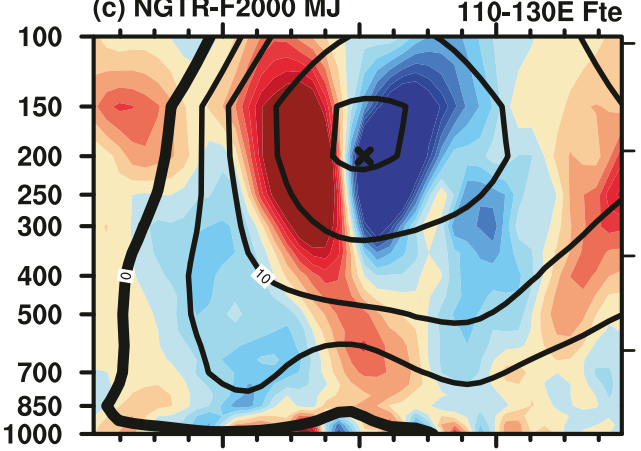

25

35

(e) NGTR-F2000 MJ

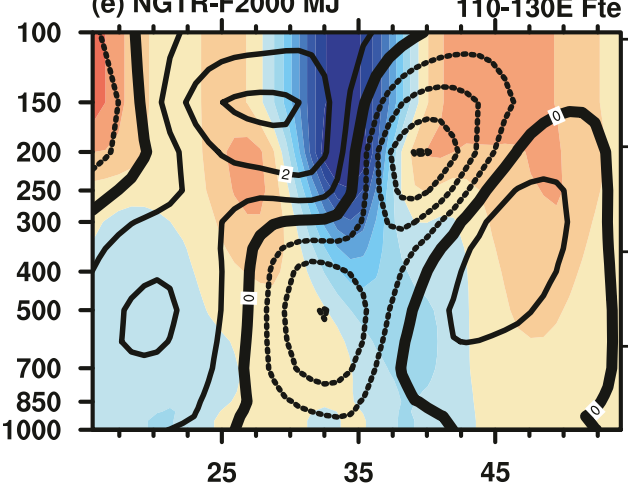

(b) F2000 JA

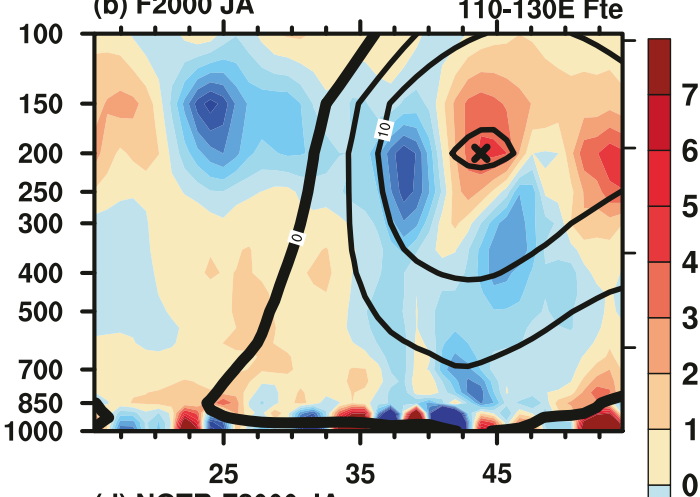

(d) NGTR-F2000 JA

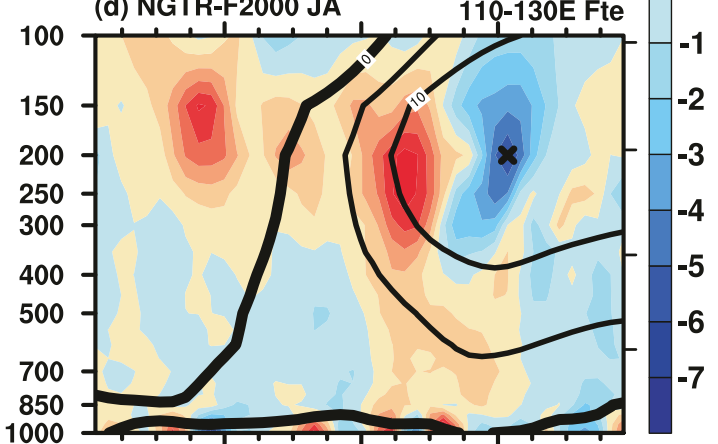

45

$25 \quad 35$

(f) NGTR-F2000 JA

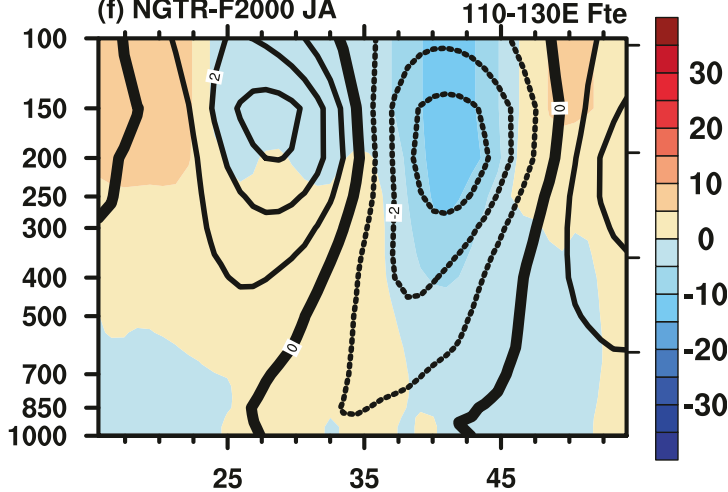

FIG. 7. As in Fig. 5, but for climatological transient eddy vorticity forcing $\left(10^{-11} \mathrm{~s}^{-2}\right)$. Positive values in (a)-(d) denote the convergence of TE vorticity flux.

wind component $\left(v_{\mathrm{ag}}>0\right)$ in the entrance region of the upperlevel westerly jet stream where the air parcels experience westerly acceleration $(d u / d t>0)$, leading to the upper-level divergence (convergence) in the southern (northern) side of the jet. A meridional secondary circulation is thus formed transverse to the jet stream, which is important for severe convective weather. The climatological material derivative of zonal wind in early summer shows that the EAWJS experiences deceleration south of the jet stream and acceleration on the northern side, causing the upper-level divergence in the south and convergence in the north (Fig. 8a). These features are consistent with the ascending region and heavy rainfall at $30^{\circ} \mathrm{N}$. In late summer, due to the westward movement of the EAWJS core (violet curves in Fig. 2), westerly deceleration is mainly seen over East Asia, accompanying the upper-level divergence and upward motion at $43^{\circ} \mathrm{N}$ (Fig. 8b).

As shown in the right column of Fig. 2, the suppression effect of the TP on TEs gradually weakens during its eastward propagation. As a result, the deceleration of the westerly wind caused by the anomalous TE vorticity forcing also weakens eastward, leading to an anomalous upper-level westerly acceleration and thus the anomalous poleward ageostrophic wind. Accordingly, there are the south divergence-north convergence anomalies in the upper troposphere, favoring the anomalous ascent around $30^{\circ} \mathrm{N}$ and anomalous descent around $42^{\circ} \mathrm{N}$ (Fig. 8d). Therefore, this anomalous upper-level divergence is conducive to the equatorward movement of the East Asian rain belt shown in Figs. $3 \mathrm{c}$ and $4 \mathrm{c}$, which can also 
(a) F2000 MJ

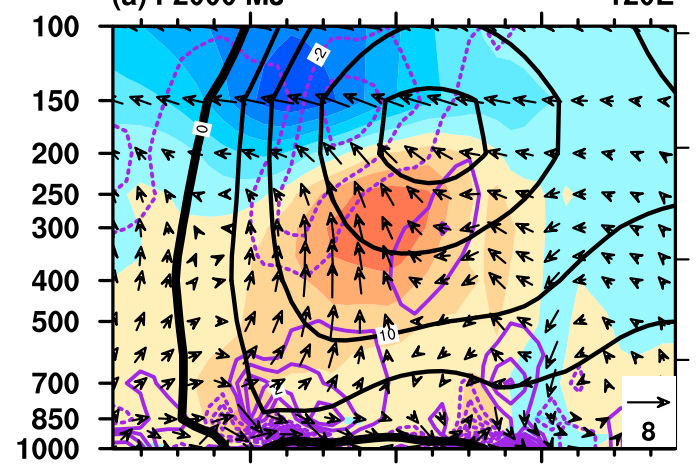

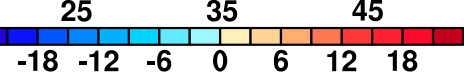

(c) NGTR-F2000 MJ
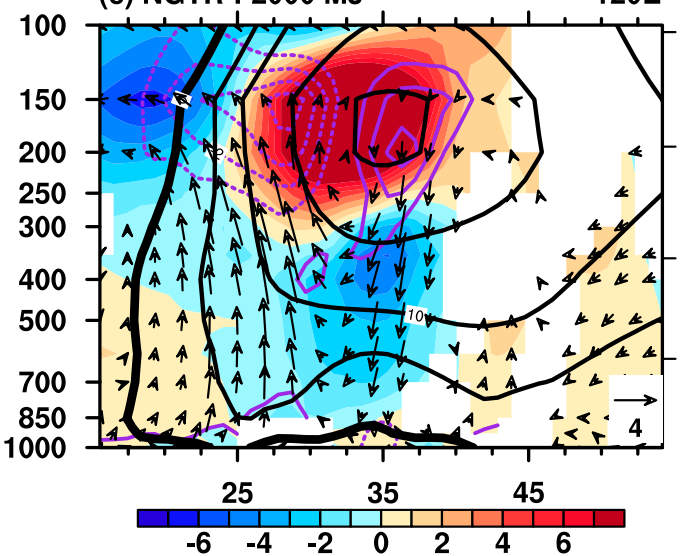

(b) F2000 JA

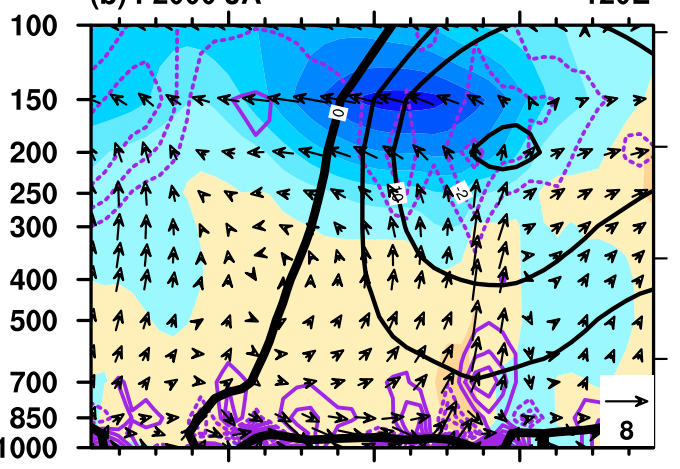

25

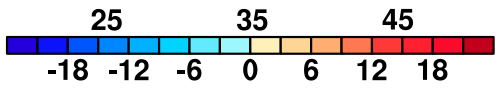

(d) NGTR-F2000 JA
$120 \mathrm{E}$
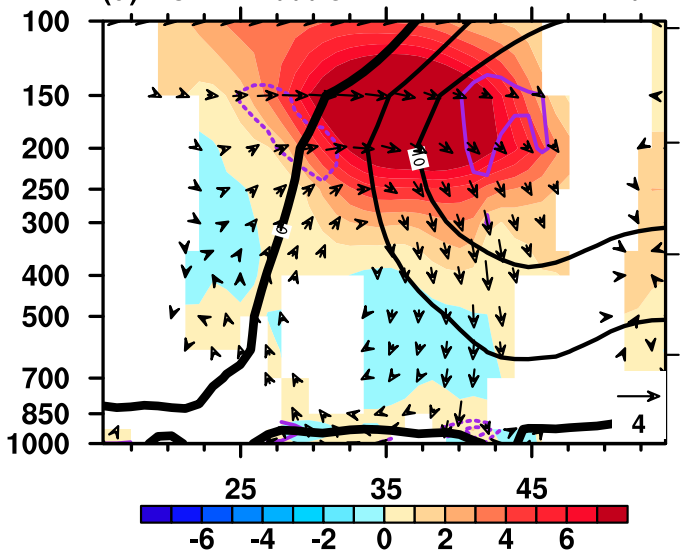

FIG. 8. Latitude-altitude sections of the climatological material derivative of zonal wind $\left(10^{-5} \mathrm{~m} \mathrm{~s}^{-2}\right.$; shading), horizontal divergence $\left[10^{-6} \mathrm{~s}^{-1}\right.$; solid (dashed) violet contours at $1.0 \times 10^{-6} \mathrm{~s}^{-1}$ interval; positive values denote convergence], and meridional circulation ( $\mathrm{m} \mathrm{s}^{-1},-10^{-2} \mathrm{~Pa} \mathrm{~s}^{-1}$; vector) along $120^{\circ} \mathrm{E}$ in $\mathrm{F} 2000$ for (a) early summer and (b) late summer. (c),(d) As in (a) and (b), but for the difference between NGTR and F2000, in which only the values significantly exceeding the $95 \%$ confidence level of Student's two-sided $t$ test are shown. The black contours represent the climatological westerly wind (contour interval: $10 \mathrm{~m} \mathrm{~s}^{-1}$ ) in F2000 in (a) and (b) and NGTR in (c) and (d).

contribute to this anomalous divergence through strong upward motion (Fig. 8c). Since the activity of TEs is suppressed all year round in NGTR, these divergence anomalies are always present, even in the relatively dry winter when the rainfall anomalies in East Asia are very small (figure not shown), suggesting that the anomalous upper-level divergence occurs before anomalous precipitation.

Upward motion is associated with not only the upper-level divergence but also the warm advection. Through investigating the thermodynamic balance at the midtroposphere where the horizontal wind response to latent heating is small, Sampe and Xie (2010) suggested that the warm advection from the eastern TP caused by the westerly jet induced adiabatic updraft, as shown in Figs. 9a and 9b where the strong upward motion over East Asia closely follows the warm advection. When the TE suppression by the TP is reinforced, the anomalous barotropic circulation caused by the suppressed poleward TE vorticity flux (Fig. 7f) makes the warm advection weaker in northern
East Asia (NEA) and stronger in southern East Asia (SEA), leading to anomalous south upward-north downward motion (Fig. 9d) and thus favoring south more-north less rainfall anomalies.

Given the important role of water vapor in rainfall, the moisture budget is analyzed, which can be written as follows (Peixoto and Oort 1992):

$$
\frac{\partial}{\partial t}\left(\frac{1}{g} \int_{p_{t}}^{p_{s}} \bar{q} d p\right)-\frac{1}{g} \int_{p_{t}}^{p_{s}}(\nabla \cdot \bar{q} \bar{V}) d p-\frac{1}{g} \int_{p_{t}}^{p_{s}}\left(\nabla \cdot \overline{q^{\prime} V^{\prime}}\right) d p+\bar{E}=\bar{P}
$$

This suggests that precipitation $\bar{P}$ is determined by the rate of local change in total precipitable water, the vertically integrated convergence of horizontal moisture flux contributed by steady circulation and TEs, and evaporation $\bar{E}$. Since the local change rates of total precipitable water and evaporation are small compared to the vertically integrated convergence of 
(a) F2000 MJ
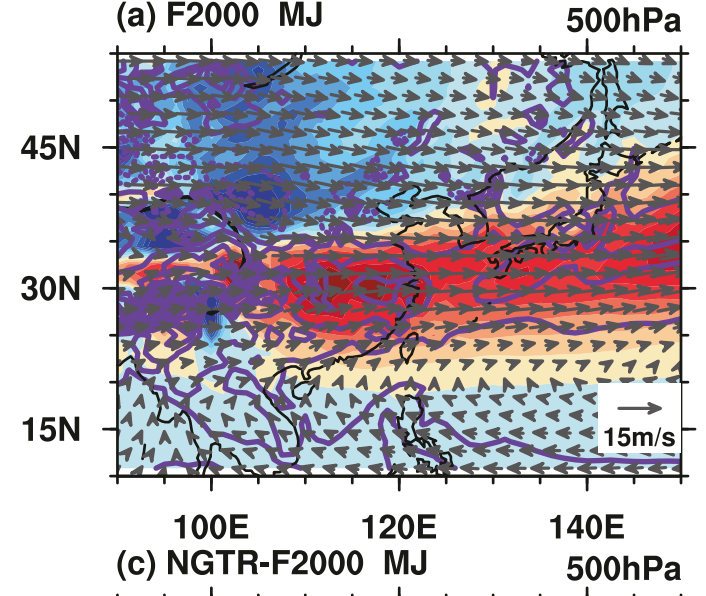

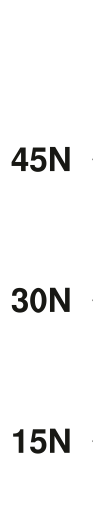

(b) F2000 JA

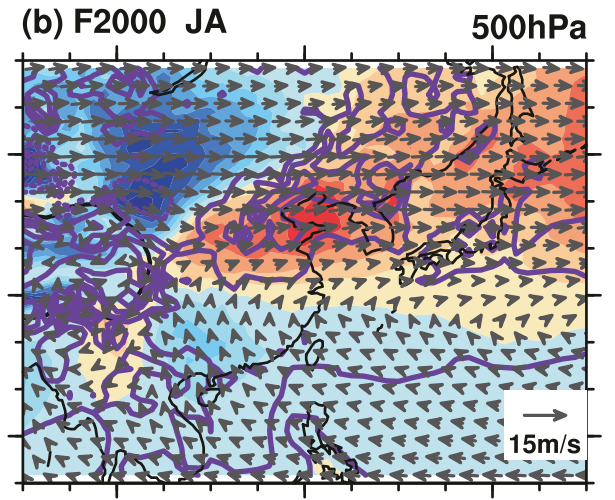

$\begin{array}{lc}\text { 100E } 120 \mathrm{E} & 140 \mathrm{E} \\ \text { (d) NGTR-F2000 JA } & 500 \mathrm{hPa}\end{array}$

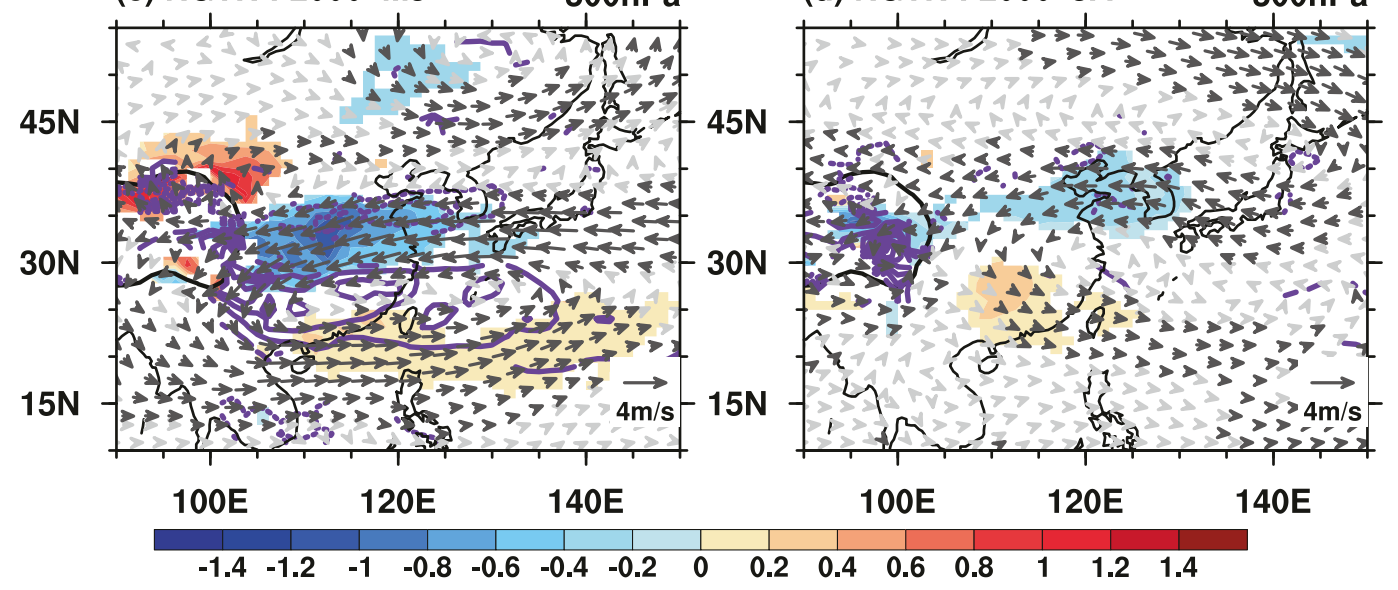

FIG. 9. Climatology of horizontal temperature advection $\left(\overline{\mathbf{V}}_{h} \cdot \nabla \bar{T} ; \mathrm{K} \mathrm{day}^{-1}\right.$; shading), horizontal wind ( $\mathrm{m} \mathrm{s}^{-1}$; vector), and vertical velocity (contour interval: $-2 \times 10^{-2} \mathrm{~Pa} \mathrm{~s}^{-1}$ ) at 500-hPa level in F2000 for (a) early and (b) late summer. Thick black curves indicate the elevation above $3000 \mathrm{~m}$. (c),(d) As in (a) and (b), respectively, but for the difference between NGTR and F2000, with color shading, black arrows, and contours (contour interval: $-10^{-2} \mathrm{~Pa} \mathrm{~s}^{-1}$ ) denoting the areas where the differences significantly exceed the $95 \%$ confidence level of Student's two-sided $t$ test.

moisture flux in summer over East Asia, only the role of moisture flux shown in Fig. 10 is considered (Trenberth and Guillemot 1995).

Comparing Figs. 3a, 4a, and 10a-d indicates that the East Asian rainband is mainly contributed by steady moisture flux, which is stronger than TE moisture flux. The anomalous rainfall is also mainly contributed by the anomalous steady moisture flux, as it is larger than the anomalous TE moisture flux (Figs. 10e-h). Since the anomalous steady moisture flux can be divided into the effects of changes in mean circulation and specific humidity, the following decomposition has been used to further examine the origin of anomalous steady moisture flux (Seager et al. 2010):

$$
\overline{q_{N}} \overline{V_{N}}-\overline{q_{F}} \overline{V_{F}} \approx \overline{q_{F}}\left(\overline{V_{N}}-\overline{V_{F}}\right)+\left(\overline{q_{N}}-\overline{q_{F}}\right) \overline{V_{F}},
$$

where subscripts $N$ and $F$ denote the NGTR and F2000 experiments, respectively. The results (figures not shown) indicate that the values of $\left(\overline{q_{N}}-\overline{q_{F}}\right) \overline{V_{F}}$ are small, while the values of $\overline{q_{F}}\left(\overline{V_{N}}-\overline{V_{F}}\right)$ are comparable to the anomalous steady moisture transport, and they have similar spatial pattern (Figs. 10e,f). Thus, the anomalous steady moisture fluxes are mostly governed by the anomalous circulation.

As discussed before, the anomalous circulation is largely driven by anomalous diabatic heating in early summer and by anomalous TE vorticity forcing in late summer. As the anomalous steady moisture fluxes in early summer are favorable (unfavorable) for the moisture convergence in SEA (NEA) (Fig. 10e), there is a positive feedback between the anomalous circulation and rainfall, referred to as convective feedback (Cho and Chen 1995; Chen et al. 2003). In late summer, the anomalous easterly winds roughly at $38^{\circ} \mathrm{N}$ weaken the southwest monsoon in NEA (Fig. 10b) and thus are not conducive to the steady moisture convergence here (Fig. 10f).

Considering that the anomalous easterly winds are driven by the anomalous TE vorticity forcing (Fig. 7f), which is stronger in early summer than in late summer (Fig. 7), the anomalous steady moisture transport shown in Fig. 10f also exists in early summer and is stronger. Accompanying the anomalous upperlevel divergence and the midtropospheric warm advection 


\section{(a) F2000 MJ}

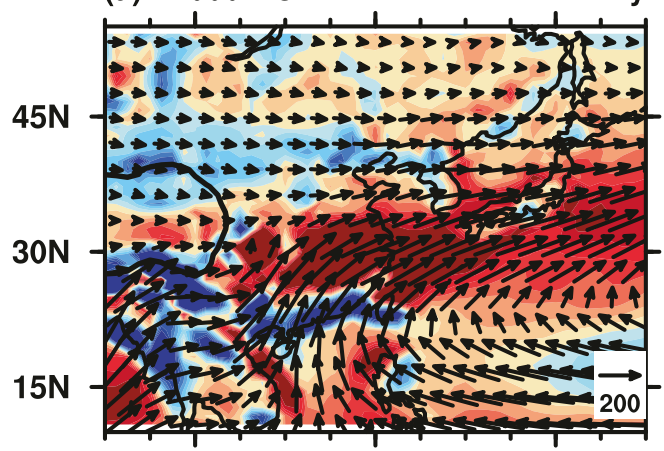

(c) F2000 MJ
Transient

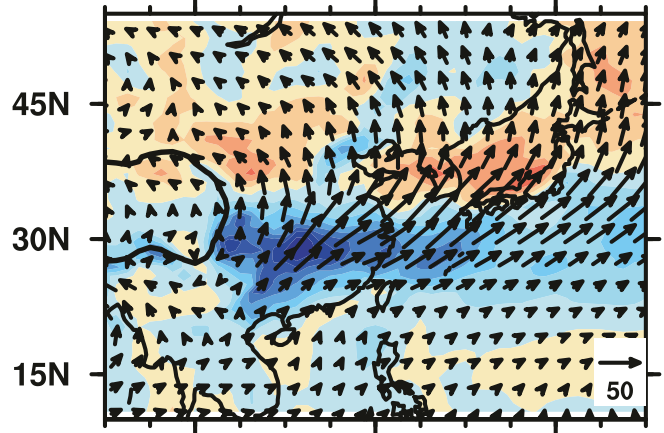
Steady

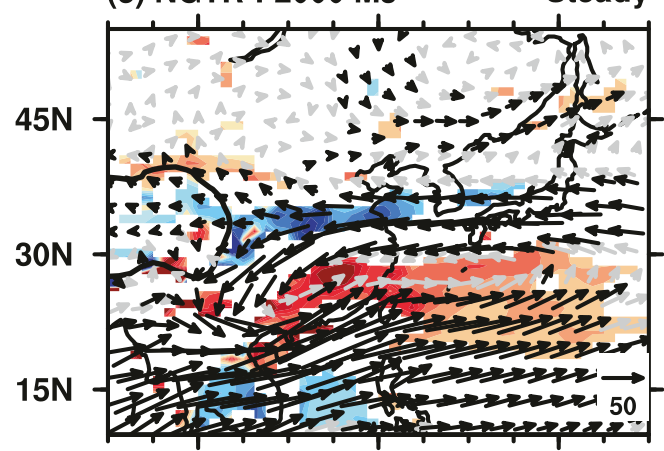

(g) NGTR-F2000 MJ

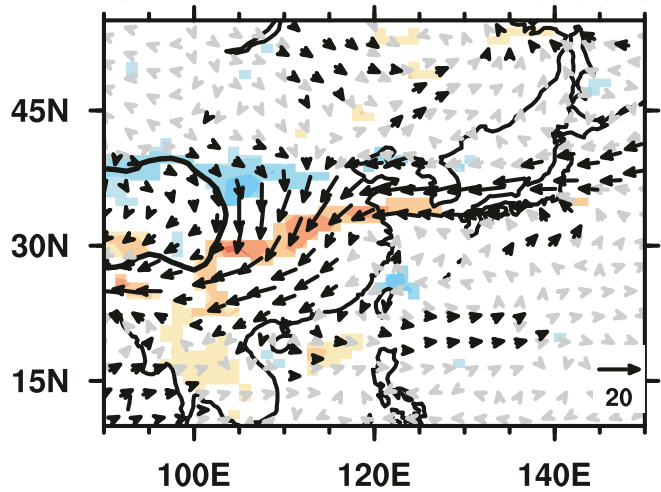

(b) F2000 JA

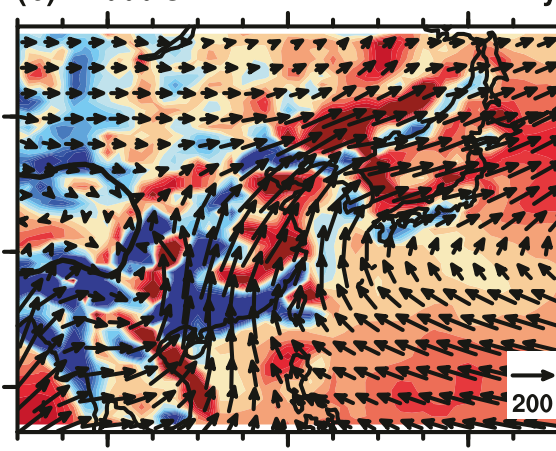

(d) F2000 JA Transient

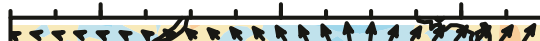

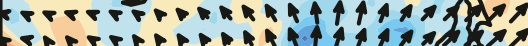

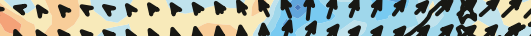

APrPRMAA A A

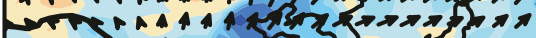

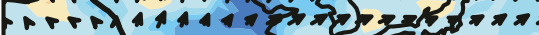

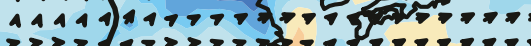

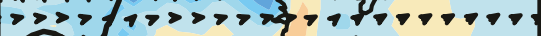

SU $\gg>>>>0,4,4 \nabla \nabla \nabla \nabla \nabla \nabla\rangle$

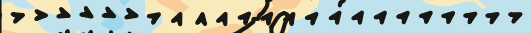

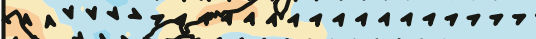

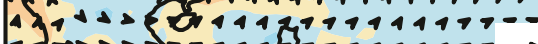

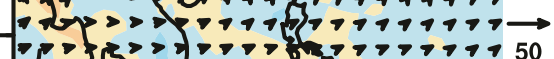

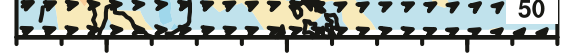

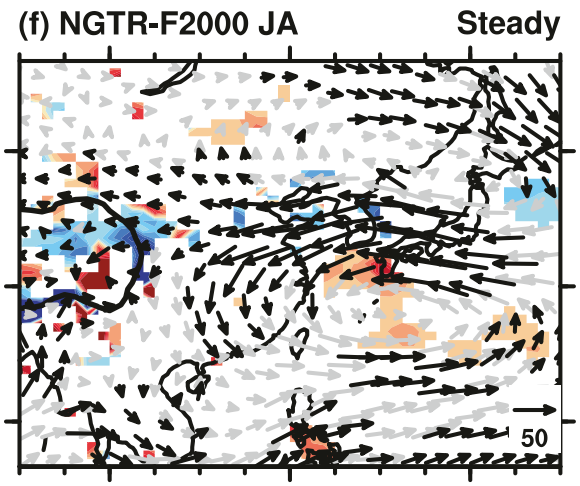

0

(h) NGTR-F2000 JA

Transient

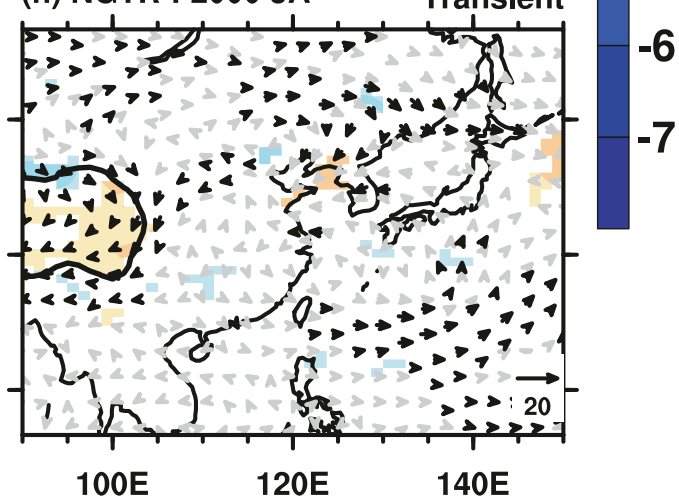

FIG. 10. Climatological vertically integrated moisture transport $\left(\mathrm{kg} \mathrm{m}^{-1} \mathrm{~s}^{-1}\right.$; vector) and its divergence $\left(10^{-5} \mathrm{~kg} \mathrm{~m}^{-2} \mathrm{~s}^{-1}\right.$; shading; positive values denote convergence) contributed by (a),(b) steady circulation $(\nabla \cdot \bar{q} \bar{V})$ and (c), (d) TEs $\left(\nabla \cdot \overline{q^{\prime} V^{\prime}}\right)$ in F2000 for (left) early summer and (right) late summer. Thick black curves indicate the elevation above $3000 \mathrm{~m}$. (e)-(h) As in (a)-(d), but for the difference between NGTR and F2000, with color shading and black arrows denoting the areas where the differences significantly exceed the $95 \%$ confidence level of Student's two-sided $t$ test. 


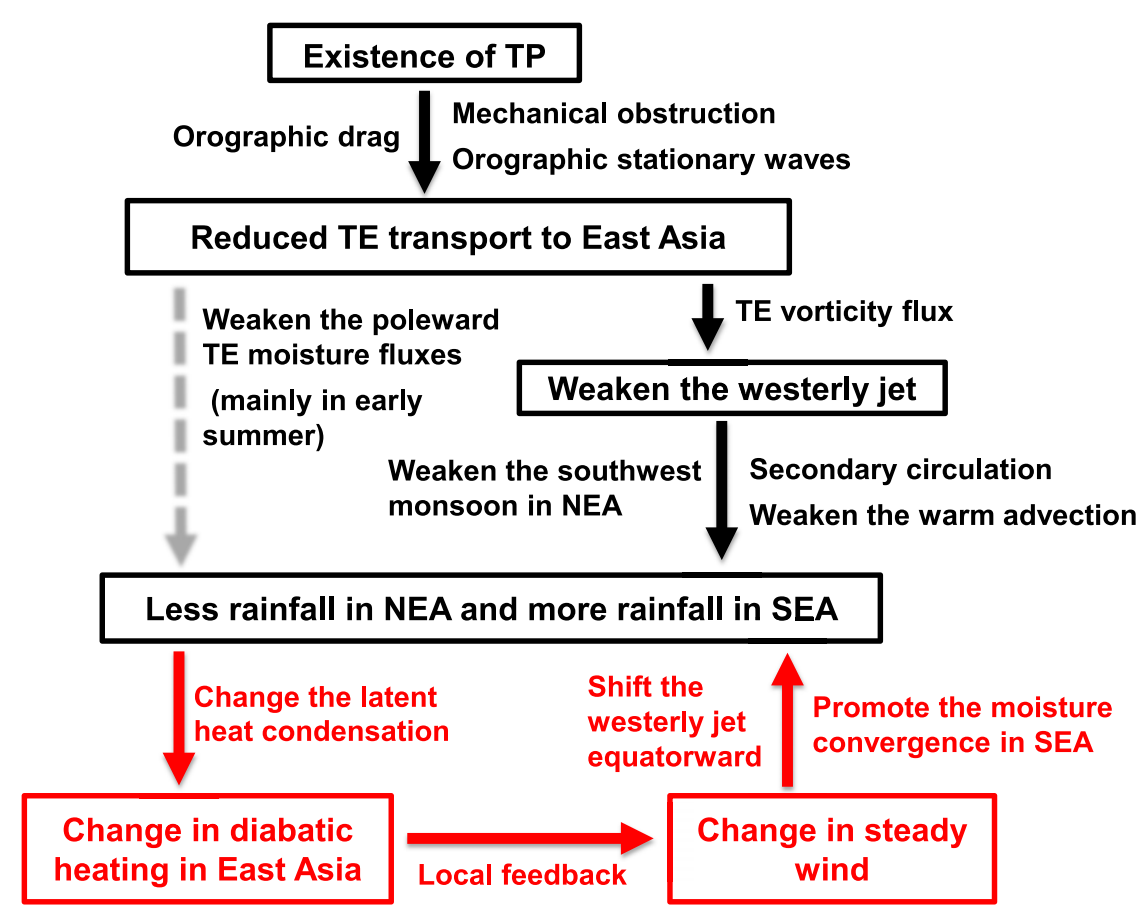

FIG. 11. Schematic diagram describing the impacts of TP on EASM via suppressed TEs. The gray dashed arrow indicates a conjecture. NEA and SEA denote northern East Asia and southern East Asia, respectively. The red part constitutes a positive feedback process, which can be called the convective feedback to amplify the anomalous precipitation pattern, especially in early summer.

that caused by the weak EAWJS, this anomalous steady moisture transport can induce the dipole rainfall anomalies in early summer, which are further amplified through convective feedback (Fig. 10e). As discussed before, this dipole rainfall anomalies can also shift the EAWJS southward through latent heat release (Fig. 5e). According to the previous studies, southward shift of the EAWJS also favors the south morenorth less rainfall anomalies (Liang and Wang 1998; Sampe and Xie 2010; Wang et al. 2018). In late summer, the weak anomalous TE vorticity forcing leads to the small changes in atmospheric circulation and rainfall and thus cannot induce convective feedback.

\section{Conclusions and discussion}

Using a nudging method in a comprehensive climate model to modify the TE suppression by the TP without changing the steady dynamic and thermodynamic effects of the plateau, we investigate the effects of the persistently suppressed TEs by the TP on the EASM. A physical mechanism is proposed, as shown in Fig. 11. The existence of the TP persistently suppresses the TEs transported from upstream to downstream regions, leading to weak TEs over East Asia. The resultant reduced poleward TE vorticity flux weakens the EAWJS, which can cause the following three processes: 1 ) generating a pattern of anomalous south divergence-north convergence circulation in the upper troposphere, 2) weakening the midtropospheric warm advection in NEA, and 3) diminishing the moisture convergence in NEA that contributed by the southwest monsoon. All of these processes favor the south more-north less rainfall anomalies over East Asia. The anomalous latent heat released by the precipitation anomalies induces the anomalous circulations that can promote the moisture convergence in SEA and lead to the southward shift of the EAWJS, forming a positive feedback to strengthen the anomalous precipitation pattern. This process implies that TEs can influence atmospheric circulation through a convective feedback. However, the impact becomes less significant in late summer when the eastward propagation of TE suppression by the TP weakens because the westerly jet stream migrates northward.

Since the TE moisture flux can directly respond to the changes in TEs activity, it may also play a role in how the persistently suppressed TEs by the TP influence the EASM. In early summer when the rainband is primarily located in central East Asia, there is still a small amount of precipitation in NEA (Fig. 3a) where the steady moisture flux converges weakly or even diverges but the poleward TE moisture flux is strong (Figs. 10a,c), suggesting the potential role of TEs in the NEA precipitation. When the TEs transported to East Asia are further reduced by the suppression effect of the TP on TEs, the poleward TE moisture flux is directly reduced, causing more water vapor to gather in SEA (Fig. 10g) and thus favoring the anomalous dipole rainfall that can be strengthened through convective feedback. Thus, the TE moisture flux may be 
(a) MJ preci

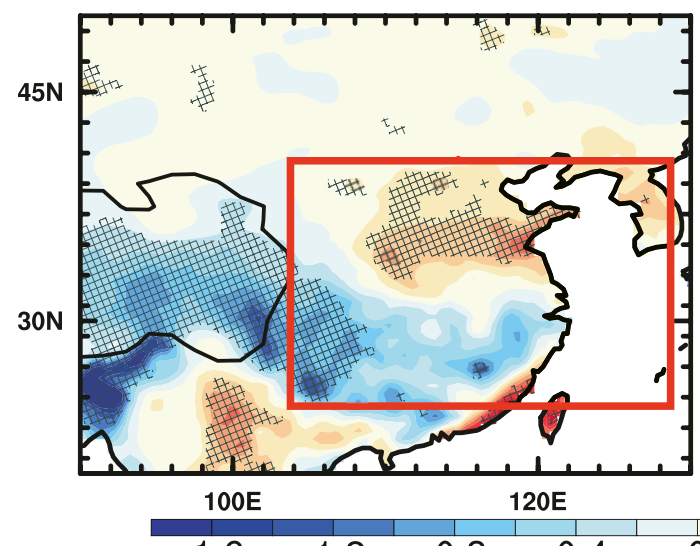

$-1.6$

$\mathrm{mm} / \mathrm{day} / 10^{5} \mathrm{~J}$ (b) JA preci

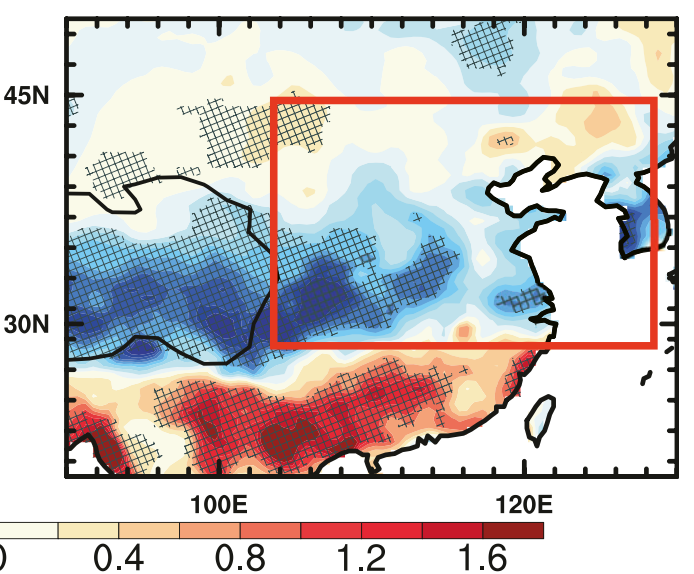

FIG. 12. One-day lagged regression of precipitation anomalies onto the 1979-2016 daily time series (annual cycle has been removed) of vertically integrated, area-averaged EKE (EKE leads) over the TP region (where the elevation is above $3000 \mathrm{~m}$ ) in (a) early summer and (b) late summer $\left[\mathrm{mm} \mathrm{day}^{-1}\left(10^{5} \mathrm{~J}\right)^{-1}\right]$. The horizontal wind is from the ERA-Interim dataset, and the daily precipitation is from the National Oceanic and Atmospheric Administration (NOAA) Climate Prediction Center (CPC) (Xie et al. 2010). The values significantly exceeding the $95 \%$ confidence level of Student's two-sided $t$ test are hatched. The anomalous dipole rainfall similar to the model results are highlighted by the red boxes.

regarded as a trigger for anomalous precipitation. In late summer, both the southwest monsoon and the resultant rainband advance to NEA, which can weaken the meridional moisture gradient and move it northward (Figs. 4a and 10b). Subsequently, the poleward TE moisture flux, which is proportional to the moisture gradient, also becomes weak and migrates northward (Fig. 10d), hinting that the climatic effect of TE moisture flux on NEA precipitation weakens in late summer. Accordingly, the change in TE moisture flux induced by the suppressed TE becomes too trivial to affect the distribution of water vapor (Fig. 10h), consistent with the weak rainfall anomalies in late summer. However, due to the small values of anomalous TE moisture flux, the above process represented by a dashed arrow in Fig. 11 is a conjecture that needs further investigations.

In the above process of TEs affecting East Asian rainfall, the convective feedback plays an important role, which depends on convective and cloud parameterizations in model simulation, suggesting that the relationship between precipitation and TEs needs to be validated. Thus, reanalysis data are used to analyze the 1-day lagged regressed anomalies of precipitation upon the daily time series of vertically integrated area-averaged EKE over the TP region in summer (Fig. 12). The regression pattern shown in Fig. 12a indicates that strong activity of TEs over the TP, or the weak TE suppression in the TP, can lead to more (less) rainfall in NEA (SEA), which is the inverse of the model results in which the TE suppression by the TP is reinforced. In late summer, the dipole-like rainfall anomalies become weak and move northward (Fig. 12b), consistent with the model results. Therefore, these regression patterns, to a certain extent, support the existence of the relationship between rainfall and TEs. However, there is more rainfall in South China when the
TE over the TP is enhanced (Fig. 12b), which does not occur in the model results. Due to the weak effects of TEs on East Asian late-summer rainfall and the complexity of the real atmosphere, there may be other factors coupled with the TEs to influence the late summer rainfall in South China. Besides, the large regression values can indicate not only the possible causal relationship but also the possibility that they may be caused by another common factor. Thus, the relationship between rainfall and TEs needs to be further investigated using observational data.

While previous studies mainly focused on the thermal and mechanical roles of the TP in the EASM and claimed that the existence of the TP favors a poleward shift of East Asian summer rain belt through steady thermodynamic and dynamic forcing (e.g., Wu et al. 2012), we qualitatively illustrate that the persistent suppression of TEs by the TP can shift the East Asian rain belt southward, particularly in early summer, providing a new insight into the climatic effect of the TP. According to $\left[\left(K_{\mathrm{F} 2000}-K_{\mathrm{noTP}}\right) /\left(K_{\mathrm{NGTR}}-K_{\mathrm{F} 2000}\right)\right]\left[\left(P_{\mathrm{NGTR}}-\right.\right.$ $\left.\left.P_{\mathrm{F} 2000}\right) / P_{\mathrm{F} 2000}\right]$, where $K$ and $P$ represent the vertically integrated area-averaged EKE over the TP region (the elevation above $3000 \mathrm{~m}$ ) and precipitation over East Asia, respectively, the proportion of precipitation caused by the suppressed effect of the TP on TEs is roughly estimated in Table 1. It shows that, in early summer, almost half of the climatic rainfall in SEA is caused by the suppressed TEs over the TP. Without the suppression effect of the TP on TEs, the climatic NEA rainfall in early summer would have increased by 0.36 or 0.52 times. Although this estimation is based on the assumptions that the TE suppression by the TP can be evaluated by the difference between F2000 and noTP, and that the change in rainfall is proportional to the reduced EKE, it is still a 
TABLE 1. The proportion of precipitation caused by the suppressed effect of the TP on TEs. The term $K$ refers to the area-averaged EKE over the TP region (the elevation above $3000 \mathrm{~m}$ ) vertically integrated from 500 to $200 \mathrm{hPa}$. The numbers in the parentheses are calculated by the EKE vertically integrated from the surface to $200 \mathrm{hPa}$.

\begin{tabular}{lcc}
\hline \hline & Early summer & Late summer \\
\hline$\left(K_{\mathrm{F} 2000}-K_{\mathrm{noTP}}\right) /\left(K_{\mathrm{NGTR}}-K_{\mathrm{F} 2000}\right)$ & $1.23772(1.77638)$ & $0.255043(0.953304)$ \\
Proportion in NEA $(\%)$ & $-36.4549(-52.3205)$ & $-5.71683(-21.3684)$ \\
Proportion in SEA $(\%)$ & $54.0888(77.6289)$ & $7.66572(28.653)$ \\
\hline
\end{tabular}

worthwhile effort to examine what a role the suppressed effect of the TP on TEs plays in the EASM rainfall when the thermal and mechanical effects of the TP are unchanged. Maybe a more comprehensive experimental scheme is needed in the future to investigate the relative importance of these three TP forcings for East Asia and even global climate. Meanwhile, as the large-scale atmospheric circulation is always quasi-balanced, the diagnostics such as the geopotential tendency budget applied in this study may not accurately reflect the cause-and-effect aspect of different processes in response to the suppressed TE activity over the TP, for which more sophisticated analyses or model experiments may be needed in further investigations. In light of the strong TE activity in winter, analysis is underway to understand the effect of suppressed TEs by the TP on winter climate and the seasonal variation. Furthermore, given that the TP can weaken both high-frequency and low-frequency TEs, which exert different roles on atmospheric circulation, the effects of different frequency TEs suppressed by the TP also deserve investigation.

The TP has always been regarded as the source of severe weather systems such as plateau vortex and shear line, which migrate eastward and cause heavy rainfall downstream (Tao and Ding 1981; Li et al. 2014). This phenomenon implies that, while the TP acts as a topographic barrier to the TEs transported from upstream regions, it also locally excites TE activity that will experience a downstream development and affect the weather and climate in East Asia. Considering that the nudging method reduces the activity of TEs over the TP, the differences between NGTR and F2000 also reveal the role of TEs over the TP in the EASM, suggesting the importance of intensive observations over the plateau.

Furthermore, since the rainfall anomalies caused by suppressed TEs are similar to the pattern of decadal rainfall change over East Asia, which is always attributed to the external forcings such as the global warming and snow cover (Ding et al. 2008, 2009; Song et al. 2014), the mechanism shown in Fig. 11 suggests that atmospheric internal processes may also influence the decadal variation of the EASM, consistent with the findings by Chen et al. (2017) and Wu et al. (2019), which also needs further investigations.

Acknowledgments. The authors thank Editor Dr. Isla Ruth Simpson and the three anonymous reviewers for providing very thorough and insightful reviews of the early versions of the manuscript. They also thank Prof. Ming Cai of the Florida State University and Prof. Yi Deng of the Georgia Institute of Technology for a number of helpful discussions. This study was supported by the National Natural Science Foundation of
China (41690123, 41690120, 42088101 and 91637208), Guangdong Major Project of Basic and Applied Basic Research (Grant 2020B0301030004), the Second Tibetan Plateau Scientific Expedition and Research program (2019QZKK0106), the Strategic Priority Research Program of Chinese Academy of Sciences (Grant XDA20000000), Guangdong Province Key Laboratory for Climate Change and Natural Disaster Studies (Grant 2020B1212060025), the Pearl River S\&T Nova Program of Guangzhou (Grant 201906010054), and the Jiangsu Collaborative Innovation Center for Climate Change. Computing resource for the CESM was provided by the high-performance grid computing platform of Sun Yat-sen University, China.

\section{APPENDIX}

\section{Steady Dynamic and Thermodynamic Forcings of the TP}

Considering the important roles played by the steady dynamic and thermodynamic forcings of the TP in EASM, it is necessary to examine whether the nudging method has altered these two forcings. As introduced in section 2, the nudging method does not change the topography of the TP and the distribution of atmospheric temperature in this region. However, the dynamic forcing of the TP is related to not only topography, but also the upstream westerlies, which will interact with the topography to influence the downstream climate (Chiang et al. 2017; Kong and Chiang 2020). The thermodynamic forcing of the TP relies on both the elevated heating over the TP and its thermal contrast with the surrounding air. Thus, the anomalous temperature at the mid- to upper troposphere $(500-200 \mathrm{hPa})$, which is a final product of diabatic heating, radiative cooling, and interactions among them (Son et al. 2019; Li and Xiao 2020), and anomalous wind at 700 and $200 \mathrm{hPa}$ in early and late summers (Figs. A1 and A2 ) have been examined.

In early summer, with the domination by the westerly wind over the TP, the nudging method mainly suppresses the TEs over the TP and thus weakens the TEs over East Asia (Figs. 2b,d). But the resultant circulation anomalies not only occur in the East Asia, but also in the North Pacific, North America, the North Atlantic, and central Eurasia. The anomalous circulation over East Asia exhibits a baroclinic structure while the others are barotropic (Figs. A1a and A2a). Since the main anomalous rainfall is located in the East Asia (Fig. A2a), the anomalous circulation here is mainly caused by the anomalous latent heating while the others are driven by the anomalous East Asian rainfall through circumglobal teleconnection (Ding and Wang 2005; Zhou et al. 2020). Anomalous circulations over central Eurasia and South Asia, to some 


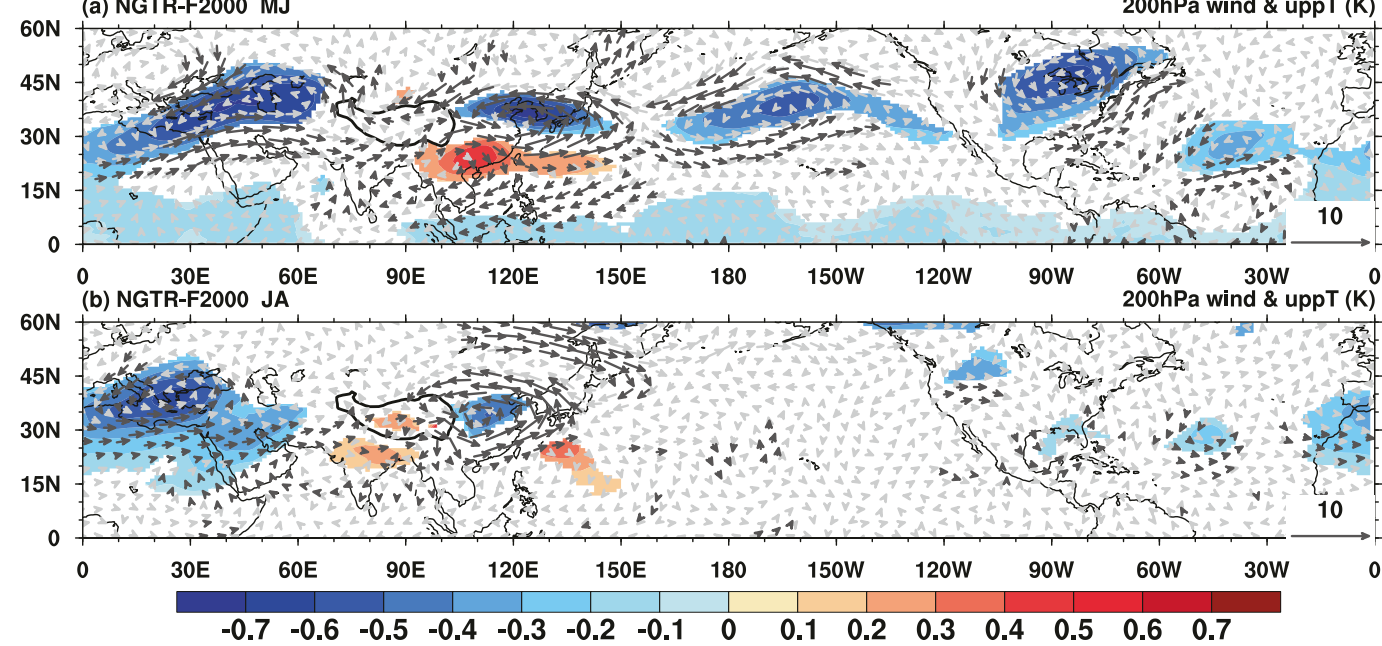

FIG. A1. Differences in air temperature averaged from 500 to $200 \mathrm{hPa}$ (K; shading) and 200-hPa horizontal wind ( $\mathrm{m} \mathrm{s}^{-1}$; vector) in (a) early and (b) late summer. Thick black curves indicate the elevation above $3 \mathrm{~km}$. Color shading and black arrows denote the areas where the differences significantly exceed the $95 \%$ confidence level of Student's two-sided $t$ test.

extent, strengthen the westerly jet stream over the upstream region of TP and its south side. According to previous studies, the enhanced westerly jet stream can reinforce the dynamic forcing of the TP, leading to the strengthened lower-level southerly (northerly) winds in SEA (NEA) (Chen and Bordoni 2014; Kong and Chiang 2020). But the anomalous 700-hPa northerly (southerly) winds in SEA (NEA) (Fig. A2a) are not consistent with the condition of reinforced dynamic forcing of the TP. Thus, the small change in upstream westerlies cannot vary the dynamic forcing of the TP. In late summer, due to the small rainfall change in East Asia, circumglobal teleconnection becomes weak (Fig. A1b). However, since the tropical easterlies move to the southern TP, the suppression effect of the TP on TEs spreads to the Iranian Plateau and the Arabian Peninsula (Figs. 2f,h), and affects the regional rainfall and atmospheric circulation. The mechanism of this upstream impact needs further investigation. The anomalous circulations in both upper and lower levels are weaker than that in early summer, hinting that this anomalous circulation also cannot change the dynamic forcing of the TP. A discontinuity between the anomalous $700-\mathrm{hPa}$ circulations over East Asia and the south of the TP also suggests this point (Fig. A2b).

It is well known that the thermal forcing of the TP induces a strong anticyclone in the upper troposphere. In NGTR, anomalous rainfall and circulation can change the air temperature through latent heat release and thermal advection

(a) NGTR-F2000 MJ

700hPa wind \& preci ( $\mathrm{mm} /$ day)

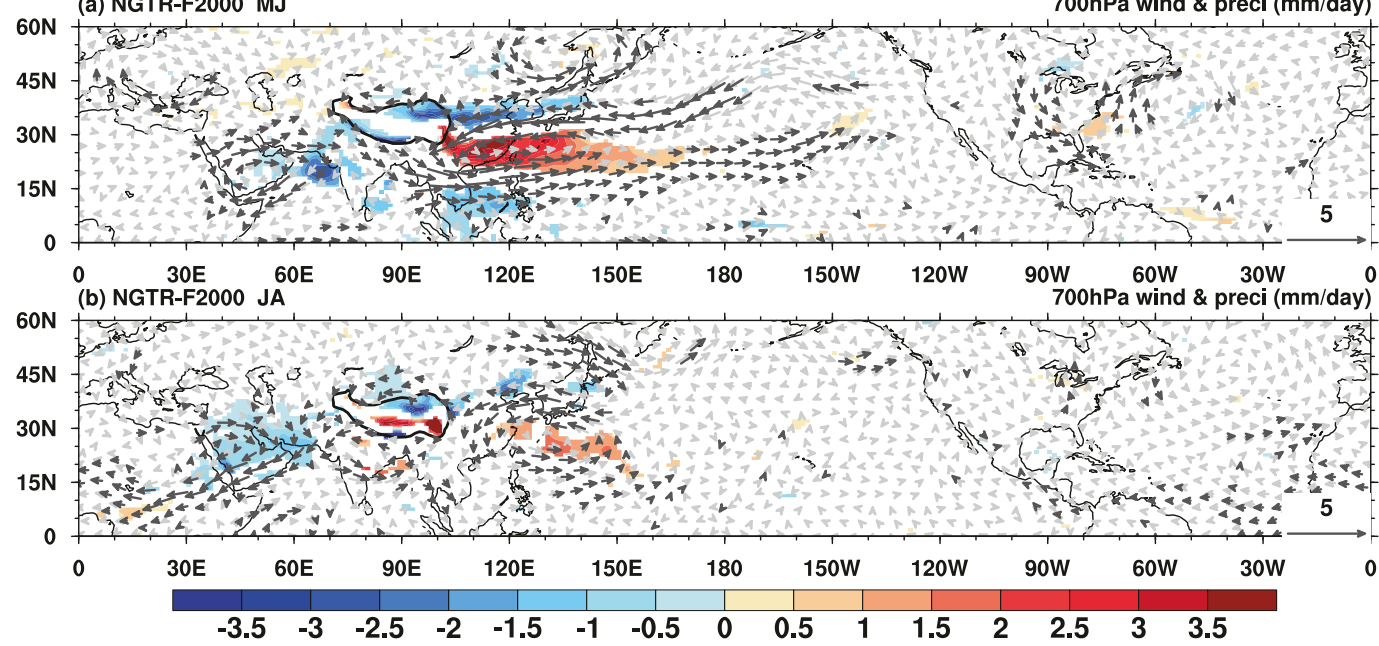

FIG. A2. As in Fig. A1, but for the differences in precipitation ( $\mathrm{mm} \mathrm{day}^{-1}$; shading) and 700-hPa horizontal wind ( $\mathrm{m} \mathrm{s}^{-1}$; vector). 
(Fig. A1), respectively, which may influence the thermal forcing of the TP. In early summer, anomalous cold air over the NEA strengthens the zonal thermal contrast between the TP and East Asia, leading to the intensified upper-level northerlies over the eastern TP. Since the temperature over the TP region has been nudged in NGTR, which leads to the unaltered elevated heating, this anomalous circulation is more like a direct response to the anomalous latent heating over NEA, and so is the anomalous circulation in SEA (Fig. A1a). The thermal condition in late summer is similar to that in early summer, except that the warming over the SEA weakens and the slight warming occurs over the south of TP. Compared with the anomalous cold air in the NEA, the anomalous warming over the south of TP is too small to induce the anomalous circulation here (Fig. A1b). Hence, it can be said that the thermodynamic effect of the TP on the EASM remains effectively unchanged.

\section{REFERENCES}

Bordoni, S., and T. Schneider, 2008: Monsoons as eddy-mediated regime transitions of the tropical overturning circulation. Nat. Geosci., 1, 515-519, https://doi.org/10.1038/ngeo248.

Cai, M., S. Yang, H. van den Dool, and V. Kousky, 2007: Dynamical implications of the orientation of atmospheric eddies: A local energetics perspective. Tellus, 59A, 127-140, https://doi.org/10.1111/j.1600-0870.2006.00213.x.

Chang, E. K. M., 2009: Diabetic and orographic forcing of northern winter stationary waves and storm tracks. J. Climate, 22, 670 688, https://doi.org/10.1175/2008JCLI2403.1.

- S. Lee, and K. L. Swanson, 2002: Storm track dynamics. J. Climate, 15, 2163-2183, https://doi.org/10.1175/1520-0442(2002) 015<02163:STD > 2.0.CO;2.

Chen, G. T.-J., C. C. Wang, and S. C.-S. Liu, 2003: Potential vorticity diagnostics of a mei-yu front case. Mon. Wea. Rev., 131, 2680-2696, https://doi.org/10.1175/1520-0493(2003)131<2680: PVDOAM $>2.0 . \mathrm{CO} ; 2$.

Chen, H., F. Teng, W. Zhang, and H. Liao, 2017: Impacts of anomalous midlatitude cyclone activity over East Asia during summer on the decadal mode of East Asian summer monsoon and its possible mechanism. J. Climate, 30, 739-753, https:// doi.org/10.1175/JCLI-D-16-0155.1.

Chen, J., and S. Bordoni, 2014: Orographic effects of the Tibetan Plateau on the East Asian summer monsoon: An energetic perspective. J. Climate, 27, 3052-3072, https://doi.org/10.1175/ JCLI-D-13-00479.1.

Chiang, J. C. H., and Coauthors, 2015: Role of seasonal transitions and westerly jets in East Asian paleoclimate. Quat. Sci. Rev., 108, 111-129, https://doi.org/10.1016/j.quascirev.2014. 11.009 .

— L. M. Swenson, and W. Kong, 2017: Role of seasonal transitions and the westerlies in the interannual variability of the East Asian summer monsoon precipitation. Geophys. Res. Lett., 44, 3788-3795, https://doi.org/10.1002/2017GL072739.

Cho, H.-R., and G. T. J. Chen, 1995: Mei-yu frontogenesis. J. Atmos. Sci., 52, 2109-2120, https://doi.org/10.1175/15200469(1995)052<2109:MYF>2.0.CO;2.

Dee, D. P., and Coauthors, 2011: The ERA-Interim reanalysis: Configuration and performance of the data assimilation system. Quart. J. Roy. Meteor. Soc., 137, 553-597, https://doi.org/ 10.1002/qj.828.
Deng, J., H. Xu, N. Shi, L. Zhang, and J. Ma, 2017: Impacts of northern Tibetan Plateau on East Asian summer rainfall via modulating midlatitude transient eddies. J. Geophys. Res. Atmos., 122, 8667-8685, https://doi.org/10.1002/2017JD027034.

Ding, Q., and B. Wang, 2005: Circumglobal teleconnection in the Northern Hemisphere summer. J. Climate, 18, 3483-3505, https://doi.org/10.1175/JCLI3473.1.

Ding, Y., and J. C. L. Chan, 2005: The East Asian summer monsoon: An overview. Meteor. Atmos. Phys., 89, 117-142, https:// doi.org/10.1007/s00703-005-0125-Z.

- Z Z. Wang, and Y. Sun, 2008: Inter-decadal variation of the summer precipitation in East China and its association with decreasing Asian summer monsoon. Part I: Observed evidences. Int. J. Climatol., 28, 1139-1161, https://doi.org/10.1002/ joc.1615.

— , Y. Sun, Z. Wang, Y. Zhu, and Y. Song, 2009: Inter-decadal variation of the summer precipitation in China and its association with decreasing Asian summer monsoon. Part II: Possible causes. Int. J. Climatol., 29, 1926-1944, https://doi.org/ 10.1002/joc.1759.

Dwyer, J. G., and P. A. O'Gorman, 2017: Moist formulations of the Eliassen-Palm flux and their connection to the surface westerlies. J. Atmos. Sci., 74, 513-530, https://doi.org/10.1175/JASD-16-0111.1.

Eichelberger, S. J., and D. L. Hartmann, 2007: Zonal jet structure and the leading mode of variability. J. Climate, 20, 5149-5163, https://doi.org/10.1175/JCLI4279.1.

Fang, J., and X. Q. Yang, 2016: Structure and dynamics of decadal anomalies in the wintertime midlatitude North Pacific oceanatmosphere system. Climate Dyn., 47, 1989-2007, https:// doi.org/10.1007/s00382-015-2946-X.

Held, I. M., and M. J. Suarez, 1994: A proposal for the intercomparison of the dynamical cores of atmospheric general circulation models. Bull. Amer. Meteor. Soc., 75, 1825-1830, https://doi.org/ 10.1175/1520-0477(1994)075<1825:APFTIO > 2.0.CO;2.

Holton, J. R., 2004: An Introduction to Dynamic Meteorology. 4th ed. Academic Press, 535 pp.

Hurrell, J. W., J. J. Hack, D. Shea, J. M. Caron, and J. Rosinski, 2008: A new sea surface temperature and sea ice boundary dataset for the Community Atmosphere Model. J. Climate, 21, 5145-5153, https://doi.org/10.1175/2008JCLI2292.1.

_, and Coauthors, 2013: The Community Earth System Model: A framework for collaborative research. Bull. Amer. Meteor. Soc., 94, 1339-1360, https://doi.org/10.1175/BAMS-D-12-00121.1.

Kong, W., and J. C. H. Chiang, 2020: Interaction of the westerlies with the Tibetan Plateau in determining the mei-yu termination. J. Climate, 33, 339-363, https://doi.org/10.1175/JCLI-D-19-0319.1.

Kooperman, G. J., M. S. Pritchard, S. J. Ghan, M. Wang, R. C. J. Somerville, and L. M. Russell, 2012: Constraining the influence of natural variability to improve estimates of global aerosol indirect effects in a nudged version of the Community Atmosphere Model 5. J. Geophys. Res., 117, D23204, https:// doi.org/10.1029/2012JD018588.

Lau, N. C., and E. O. Holopainen, 1984: Transient eddy forcing of the time-mean flow as identified by geopotential tendencies. J. Atmos. Sci., 41, 313-328, https://doi.org/10.1175/15200469(1984)041<0313:TEFOTT>2.0.CO;2.

Lee, S., and H.-K. Kim, 2003: The dynamical relationship between subtropical and eddy-driven jets. J. Atmos. Sci., 60, 1490-1503, https://doi.org/10.1175/1520-0469(2003)060<1490: TDRBSA $>2.0 . \mathrm{CO} ; 2$.

Lee, S.-S., J.-Y. Lee, K.-J. Ha, B. Wang, A. Kitoh, Y. Kajikawa, and M. Abe, 2013: Role of the Tibetan Plateau on the annual 
variation of mean atmospheric circulation and storm-track activity. J. Climate, 26, 5270-5286, https://doi.org/10.1175/ JCLI-D-12-00213.1.

Li, C., and J. J. Wettstein, 2012: Thermally driven and eddy-driven jet variability in reanalysis. J. Climate, 25, 1587-1596, https:// doi.org/10.1175/JCLI-D-11-00145.1.

Li, L., R. Zhang, M. Wen, and L. Liu, 2014: Effect of the atmospheric heat source on the development and eastward movement of the Tibetan Plateau vortices. Tellus, 66A, 24451, https://doi.org/10.3402/tellusa.v66.24451.

Li, Y., Y. Deng, S. Yang, H. Zhang, Y. Ming, and Z. Shen, 2019: Multi-scale temporal-spatial variability of the East Asian summer monsoon frontal system: Observation versus its representation in the GFDL HiRAM. Climate Dyn., 52, 67876798, https://doi.org/10.1007/s00382-018-4546-z.

Li, Z., and Z. Xiao, 2020: Thermal contrast between the Tibetan Plateau and tropical Indian Ocean and its relationship to the South Asian summer monsoon. Atmos. Oceanic Sci. Lett., 14, 100002, https://doi.org/10.1016/j.aosl.2020.100002.

Liang, X.-Z., and W. Wang, 1998: Associations between China monsoon rainfall and tropospheric jets. Quart. J. Roy. Meteor. Soc., 124, 2597-2623, https://doi.org/10.1002/qj.49712455204.

Liu, Y., B. J. Hoskins, and M. Blackburn, 2007: Impact of Tibetan orography and heating on the summer flow over Asia. J. Meteor. Soc. Japan, 85B, 1-19, https://doi.org/10.2151/jmsj.85B.1.

Lorenz, D. J., and D. L. Hartmann, 2001: Eddy-zonal flow feedback in the Southern Hemisphere. J. Atmos. Sci., 58, 3312-3327, https:// doi.org/10.1175/1520-0469(2001)058<3312:EZFFIT>2.0.CO;2.

Lu, M., S. Yang, J. Wang, Y. Wu, and X. Jia, 2021: Response of regional Asian summer monsoons to the effect of reduced surface albedo in different Tibetan Plateau domains in idealized model experiments. J. Climate, 34, 7023-7036, https:// doi.org/10.1175/JCLI-D-20-0500.1.

Mayooran, T., and E. Light, 2016: Applying the successive overrelaxation method to a real world problems. Amer. J. Appl. Math. Stat., 4, 113-117, https://doi.org/10.12691/ajams-4-4-3.

Molnar, P., W. R. Boos, and D. S. Battisti, 2010: Orographic controls on climate and paleoclimate of Asia: Thermal and mechanical roles for the Tibetan Plateau. Annu. Rev. Earth Planet. Sci., 38, 77-102, https://doi.org/10.1146/annurev-earth040809-152456.

Nie, Y., Y. Zhang, X. Q. Yang, and G. Chen, 2013: Baroclinic anomalies associated with the Southern Hemisphere annular mode: Roles of synoptic and low-frequency eddies. Geophys. Res. Lett., 40, 2361-2366, https://doi.org/10.1002/grl.50396.

Ólafsson, H., and P. Bougeault, 1997: The effect of rotation and surface friction on orographic drag. J. Atmos. Sci., 54, 193-210, https://doi.org/10.1175/1520-0469(1997)054<0193: TEORAS $>2.0 . \mathrm{CO} ; 2$.

Park, H.-S., J. C. H. Chiang, and S.-W. Son, 2010: The role of the central Asian mountains on the midwinter suppression of North Pacific storminess. J. Atmos. Sci., 67, 3706-3720, https:// doi.org/10.1175/2010JAS3349.1.

_ _ _ - and S. Bordoni, 2012: The mechanical impact of the Tibetan Plateau on the seasonal evolution of the South Asian monsoon. J. Climate, 25, 2394-2407, https://doi.org/10.1175/ JCLI-D-11-00281.1.

_- S.-P. Xie, and S.-W. Son, 2013: Poleward stationary eddy heat transport by the Tibetan Plateau and equatorward shift of westerlies during northern winter. J. Atmos. Sci., 70, 32883301, https://doi.org/10.1175/JAS-D-13-039.1.

- B. R. Lintner, W. R. Boos, and K.-H. Seo, 2015: The effect of midlatitude transient eddies on monsoonal southerlies over eastern China. J. Climate, 28, 8450-8465, https://doi.org/ 10.1175/JCLI-D-15-0133.1.

Peixoto, J. P., and A. H. Oort, 1992: Physics of Climate. American Institute of Physics, $520 \mathrm{pp}$.

Queney, P., 1948: The problem of air flow over mountains: A summary of theoretical studies. Bull. Amer. Meteor. Soc., 29, 16-26, https://doi.org/10.1175/1520-0477-29.1.16.

Sampe, T., and S. P. Xie, 2010: Large-scale dynamics of the meiyu-baiu rainband: Environmental forcing by the westerly jet. J. Climate, 23, 113-134, https://doi.org/10.1175/2009JCLI3128.1.

Schiemann, R., D. Lüthi, and C. Schär, 2009: Seasonality and interannual variability of the westerly jet in the Tibetan Plateau region. J. Climate, 22, 2940-2957, https://doi.org/ 10.1175/2008JCLI2625.1.

Schneider, T., and S. Bordoni, 2008: Eddy-mediated regime transitions in the seasonal cycle of a Hadley circulation and implications for monsoon dynamics. J. Atmos. Sci., 65, 915-934, https://doi.org/10.1175/2007JAS2415.1.

Seager, R., N. Naik, and G. A. Vecchi, 2010: Thermodynamic and dynamic mechanisms for large-scale changes in the hydrological cycle in response to global warming. J. Climate, $\mathbf{2 3}$, 4651-4668, https://doi.org/10.1175/2010JCLI3655.1.

Shi, N., and C. Bueh, 2013: Three-dimensional dynamic features of two Arctic Oscillation types. Adv. Atmos. Sci., 30, 1039-1052, https://doi.org/10.1007/s00376-012-2077-9.

Son, J.-H., K.-H. Seo, and B. Wang, 2019: Dynamical control of the Tibetan Plateau on the East Asian summer monsoon. Geophys. Res. Lett., 46, 7672-7679, https://doi.org/10.1029/2019GL083104.

Son, S.-W., M. Ting, and L. M. Polvani, 2009: The effect of topography on storm-track intensity in a relatively simple general circulation model. J. Atmos. Sci., 66, 393-411, https:// doi.org/10.1175/2008JAS2742.1.

Song, F., T. Zhou, and Y. Qian, 2014: Responses of East Asian summer monsoon to natural and anthropogenic forcings in the 17 latest CMIP5 models. Geophys. Res. Lett., 41, 596-603, https://doi.org/10.1002/2013GL058705.

Tang, Q., and Coauthors, 2019: Regionally refined test bed in E3SM atmosphere model version 1 (EAMv1) and applications for high-resolution modeling. Geosci. Model Dev., 12, 26792706, https://doi.org/10.5194/gmd-12-2679-2019.

Tao, S., and Y. Ding, 1981: Observational evidence of the influence of the Qinghai-Xizang (Tibet) plateau on the occurrence of heavy rain and severe convective storms in China. Bull. Amer. Meteor. Soc., 62, 23-30, https://doi.org/10.1175/ 1520-0477(1981)062<0023:OEOTIO > 2.0.CO;2.

Trenberth, K. E., and C. J. Guillemot, 1995: Evaluation of the global atmospheric moisture budget as seen from analyses. J. Climate, 8, 2255-2272, https://doi.org/10.1175/ 1520-0442(1995)008<2255:EOTGAM >2.0.CO;2.

Wang, B., and LinHo, 2002: Rainy season of the Asian-Pacific summer monsoon. J. Climate, 15, 386-398, https://doi.org/ 10.1175/1520-0442(2002)015<0386:RSOTAP $>2.0$.CO;2.

—, Q. Bao, B. Hoskins, G. Wu, and Y. Liu, 2008: Tibetan Plateau warming and precipitation changes in East Asia. Geophys. Res. Lett., 35, L14702, https://doi.org/10.1029/2008GL034330.

Wang, S., H. Zuo, S. Zhao, J. Zhang, and S. Lu, 2018: How East Asian westerly jet's meridional position affects the summer rainfall in Yangtze-Huaihe River Valley? Climate Dyn., 51, 4109-4121, https://doi.org/10.1007/s00382-017-3591-3.

Wu, G., 1984: The nonlinear response of the atmosphere to large-scale mechanical and thermal forcing. J. Atmos. Sci., 41, 2456-2476, https://doi.org/10.1175/1520-0469(1984)041<2456: TNROTA $>2.0 . \mathrm{CO} ; 2$. 
and Coauthors, 2007: The influence of mechanical and thermal forcing by the Tibetan Plateau on Asian climate. J. Hydrometeor., 8, 770-789, https://doi.org/10.1175/JHM609.1.

—, Y. Liu, B. He, Q. Bao, A. Duan, and F.-F. Jin, 2012: Thermal controls on the Asian summer monsoon. Sci. Rep., 2, 404, https://doi.org/10.1038/srep00404.

— , and Coauthors, 2015: Tibetan Plateau climate dynamics: Recent research progress and outlook. Natl. Sci. Rev., 2, 100116, https://doi.org/10.1093/nsr/nwu045.

Wu, R., T. You, and K. Hu, 2019: What formed the north-south contrasting pattern of summer rainfall changes over eastern China? Curr. Climate Change Rep., 5, 47-62, https://doi.org/ 10.1007/s40641-019-00124-z.

Xiang, Y., and X. Yang, 2012: The effect of transient eddy on interannual meridional displacement of summer East Asian subtropical jet. Adv. Atmos. Sci., 29, 484-492, https://doi.org/ 10.1007/s00376-011-1113-5.

Xie, P., M. Chen, and W. Shi, 2010: CPC global unified gauge-based analysis of daily precipitation. 24th. Conf. on Hydrology, Atlanta, GA, Amer. Meteor. Soc., 2.3A, https://ams.confex.com/ ams/90annual/techprogram/paper_163676.htm.

Yamada, R., and O. Pauluis, 2017: Wave-mean-flow interactions in moist baroclinic life cycles. J. Atmos. Sci., 74, 2143-2162, https://doi.org/10.1175/JAS-D-16-0329.1.
Yanai, M., and T. Tomita, 1998: Seasonal and interannual variability of atmospheric heat sources and moisture sinks as determined from NCEP-NCAR reanalysis. J. Climate, 11, 463-482, https://doi.org/10.1175/1520-0442(1998)011<0463: SAIVOA $>2.0 . \mathrm{CO} ; 2$.

Yu, J. Y., and D. L. Hartmann, 1995: Orographic influences on the distribution and generation of atmospheric variability in a GCM. J. Atmos. Sci., 52, 2428-2443, https://doi.org/10.1175/ 1520-0469(1995)052<2428:OIOTDA > 2.0.CO;2.

Yuan, J., S. Lee, and B. Tan, 2013: Observational evidence for the mechanism of the poleward propagation of zonal wind anomalies over the North Atlantic. Quart. J. Roy. Meteor. Soc., 139, 992-998, https://doi.org/10.1002/qj.2010.

Zhang, Q., Y. Zheng, V. P. Singh, M. Luo, and Z. Xie, 2017: Summer extreme precipitation in eastern China: Mechanisms and impacts. J. Geophys. Res. Atmos., 122, 2766-2778, https:// doi.org/10.1002/2016JD025913.

Zhang, Y., X. Q. Yang, Y. Nie, and G. Chen, 2012: Annular mode-like variation in a multilayer quasigeostrophic model. J. Atmos. Sci., 69, 2940-2958, https://doi.org/10.1175/JASD-11-0214.1.

Zhou, F., R. Zhang, and J. Han, 2020: Influences of the East Asian summer rainfall on circumglobal teleconnection. J. Climate, 33, 5213-5221, https://doi.org/10.1175/JCLI-D-19-0325.1. 